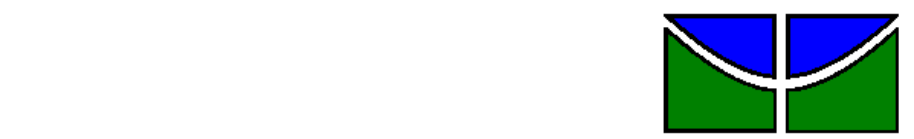

Universidade de Brasília

Faculdade de Economia, Administração, Contabilidade e Ciências da Informação e Documentação Departamento de Administração

\title{
INFLUÊNCIA DAS ESTRATÉGIAS DE PROPAGANDA E PREÇO NA PARTICIPAÇÃO DE MERCADO: CONTROLE DO BENEFÍCIO INFORMATIVO EM PRODUTOS ESSENCIAIS E SUPÉRFLUOS
}

Brasília - DF 


\section{LUCIANA BABILÔNIA DE MELO}

\section{INFLUÊNCIA DAS ESTRATÉGIAS DE PROPAGANDA E PREÇO NA PARTICIPAÇÃO DE MERCADO: CONTROLE DO BENEFÍCIO INFORMATIVO EM PRODUTOS ESSENCIAIS E SUPÉRFLUOS}

Monografia apresentada ao

Departamento de Administração como requisito parcial à obtenção do título de Bacharel em Administração.

Professor Orientador: Dr. Rafael Barreiros Porto. 
Melo, Luciana Babilônia.

Influência das Estratégias de Propaganda e Preço na Participação de Mercado: Controle do Benefício Informativo em Produtos Essenciais e Supérfluos / Luciana Babilônia de Melo. - Brasília, 2010.

$61 \mathrm{f}$ : : il.

Monografia (bacharelado) - Universidade de Brasília, Departamento de Administração, 2010.

Orientador: Prof. Dr. Rafael Barreiros Porto, Departamento de Administração.

1. Fatia de Mercado. 2. Estratégias de Marketing.

3. Benefício Informativo. 4. Produtos Essenciais e Supérfluos. 


\title{
INFLUÊNCIA DAS ESTRATÉGIAS DE PROPAGANDA E PREÇO NA PARTICIPAÇÃO DE MERCADO: CONTROLE DO BENEFÍCIO INFORMATIVO EM PRODUTOS ESSENCIAIS E SUPÉRFLUOS
}

A Comissão Examinadora, abaixo identificada, aprova o Trabalho de Conclusão do Curso de Administração da Universidade de Brasília da aluna

\section{Luciana Babilônia de Melo}

\author{
Doutor, Rafael Barreiros Porto \\ Professor-Orientador \\ Mestre Pedro Henrique Melo \\ Albuquerque \\ Professor-Examinador \\ Doutora Amália Raquel Pérez-Nebra \\ Professora-Examinadora
}

Brasília, 30 de agosto de 2010. 
Aos grandes responsáveis por tudo isso, que eu amo tanto e que sempre me apoiaram e me deram forças: meu pai Marcelino, minha mãe Elaine e meus lindos irmãos Cristiane e Marcelo. 


\section{RESUMO}

A cada dia que passa a atividade de marketing adquire maior influência e importância perante os empresários e clientes das organizações, porém pouco se conhece sobre os verdadeiros impactos de suas estratégias de propaganda e preço. Para as marcas comercializadas no varejo, essas estratégias podem ser eficazes ou não em gerar fatias de mercados, contudo dependem dos tipos de produtos e do grau dos benefícios informativos que oferecem ao consumidor. Para melhor investigar essa situação, o objetivo geral desse trabalho foi avaliar o impacto das estratégias de marketing na fatia de mercado, com o controle dos benefícios informativos das marcas em produtos essenciais e supérfluos. Para alcançar esse objetivo foram realizados estudos com base em dados primários e secundários, onde se extraiu as variáveis independentes propaganda geral, propaganda em folhetos, preço promocional, preço premium e preço concorrencial e também a variável dependente fatia de mercado agregada e diária. Os dados referentes a fatia de mercado agregada foram calculados através da regressão linear enquanto os dados referentes a fatia de mercado diária foram calculados através da regressão ordinal. Após analisar cada caso conclui-se que para cada tipo de produto e benefício informativo existe uma ou mais estratégia de definição de preço e propaganda que pode influenciar mais ou menos em relação a fatia de mercado. Com os resultados apresentados nesse trabalho os gerentes de marketing poderão identificar qual é a estratégia mais eficiente para aumentar a fatia de mercado de suas marcas.

Palavras-chave: 1.Fatia de Mercado. 2.Estratégias de Marketing. 3.Benefício Informativo. 4.Produtos Essenciais e Supérfluos. 


\section{LISTA DE ILUSTRAÇÕES}

Figura 1 - Modelo Teórico de Foxall traduzido ...................................................... 23

Figura 2 - Modelo Empírico do Trabalho ........................................................... 26

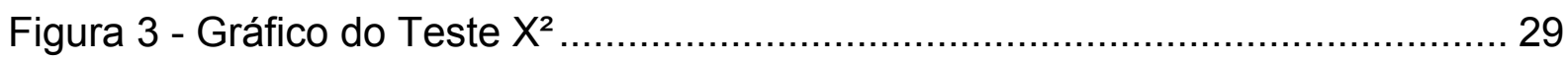

Figura 4 - Esquema de Procedimento de Coleta e Análise de Dados..................... 32

Figura 5 - Fatia de Mercado Agregada de Venda Relativa ao Produto X Quantidade

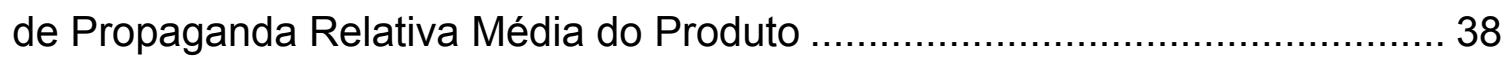

Figura 6 - Gráfico de Fatia de Mercado Total de Venda Relativa ao Produto X Preço

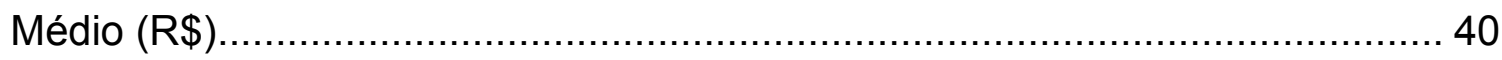

Figura 7 - Gráfico de Fatia de Mercado Diária / Fatia de mercado Média (por marca)

Figura 8 - Variação da Fatia Diária da Marca dos Produtos Essenciais de Baixo Nível Informativo. 42

Figura 9 - Variação da Fatia Diária da Marca dos Produtos Essenciais de Alto Nível Informativo. 43

Figura 10 - Variação da Fatia de Mercado Diária da Marca dos Produtos Supérfluos de Baixo Nível Informativo 44

Figura 11 - Variação da Fatia de Mercado Diária da Marca dos Produtos Supérfluos de Alto Nível Informativo 45 


\section{LISTA DE TABELAS}

Tabela 1-Percentagem de participantes que indicaram os produtos com maiores índices de indicação como consumidos regularmente. 20

Tabela 2 - Tabela Explicativa dos Cálculos de Regressão Linear de Benefício Simbólico das Marcas 34

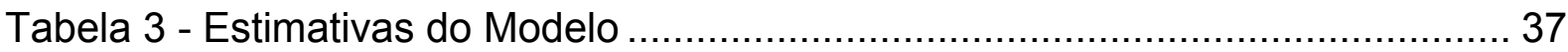

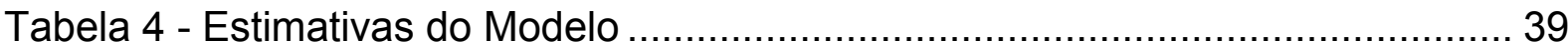

Tabela 5 - Parâmetro Estimado dos Produtos ................................................ 46

Tabela 6 - Parâmetro Estimado dos Produtos Essenciais de Nível Informativo Baixo

Tabela 7 - Parâmetro Estimado dos Produtos Essenciais de Nível Informativo Alto 48

Tabela 8 - Parâmetro Estimado dos Produtos Supérfluos de Nível Informativo Baixo 49

Tabela 9 - Parâmetro Estimado dos Produtos Supérfluos de Nível Informativo Alto 50 


\section{SUMÁRIO}

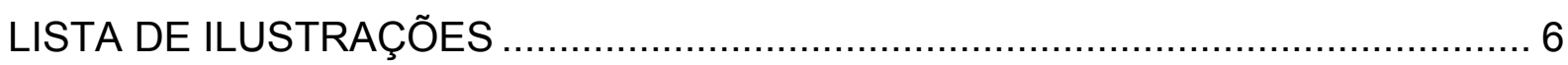

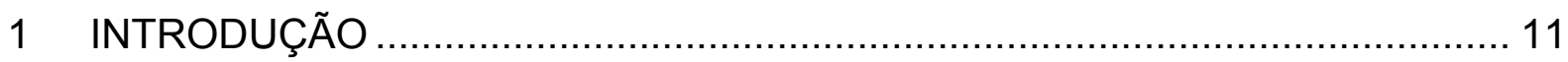

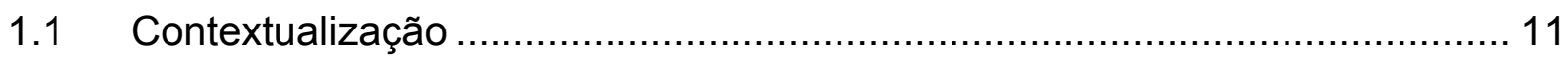

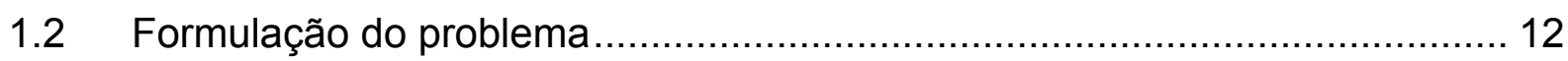

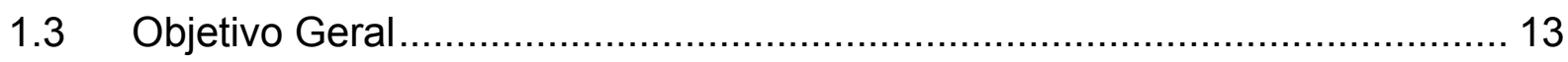

1.4 Objetivos Específicos ......................................................................... 13

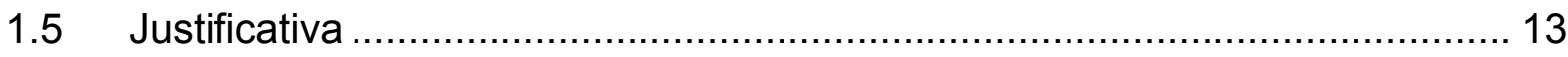

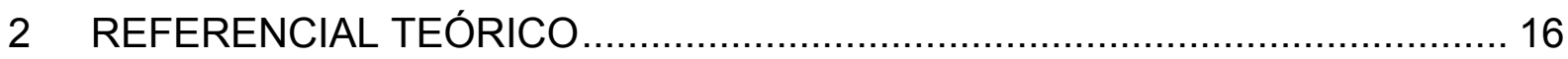

2.1 Influência das Estratégias de Marketing: Propaganda e Preço....................... 16

2.2 Fatia de Mercado de Produtos Essenciais e Supérfluos .............................. 18

2.3 Benefício Simbólico Alto e Baixo das Marcas …………............................ 21

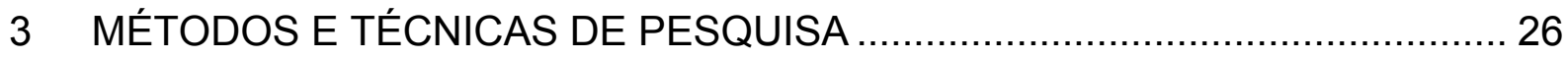

3.1 Tipo e descrição geral da pesquisa ......................................................... 26

3.2 Caracterização da organização, setor ou área............................................ 27

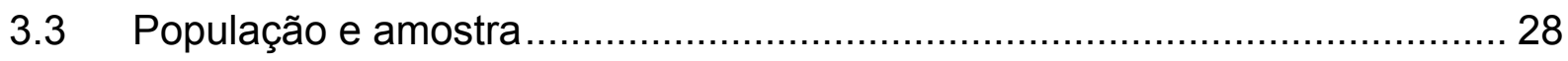

3.4 Caracterização dos instrumentos de pesquisa.............................................. 30

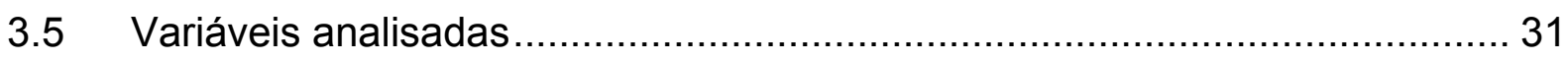

3.6 Procedimentos de coleta e de análise de dados .......................................... 32

3.6.1 Procedimento para Identificação da Influência das Estratégias de Propaganda e Preço na Participação de Mercado.................................................... 34

3.6.2 Procedimento para Identificação do Reforço Informativo da Marca ............ 36

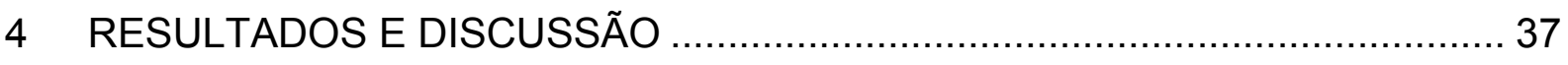

4.1 Influência das Estratégias de Propaganda e Preço na Fatia Agregada de Mercado 
4.2 Influência das Estratégias de Propaganda e Preço na Fatia Diária de Mercado com Controle dos Benefícios Informativos em Produtos Essenciais e Supérfluos ... 41

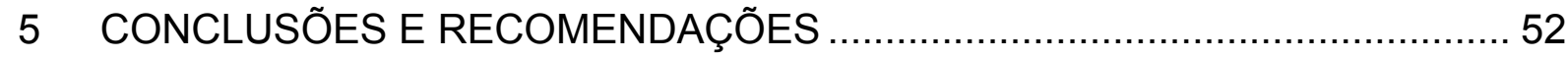

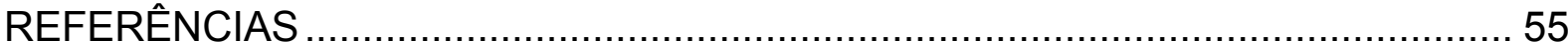

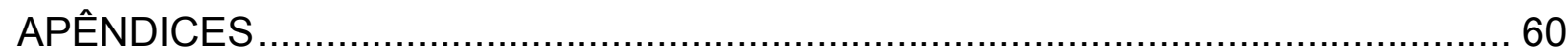

Apêndice A - Questionário De Nível Informativo ..........................................................6 60

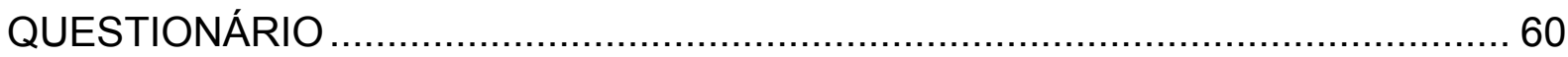




\section{INTRODUÇÃO}

\subsection{Contextualização}

A cada dia que passa o conceito de marketing adquire maior influência e importância perante os empresários e clientes de uma organização. Esse fato pode ser explicado por Neves e Pessoa (2006) quando eles afirmam que os principais motivos que levam as lojas a encerrarem suas atividades são a estagnação da economia, a concorrência acirrada, o despreparo dos lojistas para enfrentar desafios, e a falta de planejamento de marketing. Hoje, institutos de pesquisa de comunicação e organizações interessadas em conhecer seus clientes demandam metodologias capazes de detectar desde os sonhos do consumidor até suas mais prementes necessidades do dia-a-dia (PINHEIRO et alii, 2006).

O composto de marketing também denominado como mix de marketing, trata-se do conjunto de ferramentas ou variáveis de marketing que a empresa ou organização utiliza para perseguir seu objetivo de marketing no mercado-alvo (AMARAL, 2008). Neste trabalho serão estudadas as seguintes variáveis independentes: propaganda e preço.

Para Rabaça e Barbosa (1978), propaganda é qualquer forma de divulgação de produtos ou serviços através de anúncios geralmente pagos e veiculados sob a responsabilidade de um anunciante identificado, com objetivos de interesse comercial. Normalmente são utilizadas para anunciar um produto e despertar no mercado consumidor o desejo pelo que foi anunciado, com isso espera-se que através delas as vendas aumentem e cada vez mais as pessoas conheçam o produto e queiram consumi-lo. Além da propagada o preço também tem forte poder de influência sobre a escolha do consumidor por uma determinada marca. Thaler (1999) afirma que o preço percebido como justo pelo consumidor, chamado preço de referência é o que influencia a compra. Normalmente as marcas utilizam essas duas variáveis (propaganda e preço) ao mesmo tempo o que dificulta a análise de qual é a mais influente nos indicadores de desempenho mercadológicos. 
Esse projeto trata-se do estudo das estratégias de marketing no mercado varejista, onde a disputa pelo consumidor tem aumentado significativamente. Segundo Freitas (2007) um consumidor recebe em média cerca de 1800 mensagens publicitárias por dia e Aufreiter, Elzinga e Gordon (2003) complementa com o dado de que um supermercado que em 1991 tinha em média 15.000 itens na gôndola, em 2001 esse número já estava em 45.000 itens. Diante desse contexto com tantas opções para o consumidor as empresas encontram dificuldades para se diferenciar da concorrência tornando-se assim extremamente importante ter um conhecimento intenso de seus produtos e marcas e como eles se comportam em relação as propagandas e estratégias adotadas para aumentar as vendas.

O mercado varejista de alimentos possui um leque amplo de produtos o que aumenta ainda mais a necessidade de dar visibilidade ao produto e à marca através de propagandas e de preço. Existem marcas mais e menos conhecidas com percepções de qualidade diferenciadas pelo consumidor, o que explica o fato de que propagandas e preços podem impactar de forma desigual os consumidores, ou seja, uma propaganda e/ou preço de uma marca conhecida pode ter um grande impacto na escolha de produtos, enquanto a propaganda e/ou preço de uma marca menos conhecida pode não influenciar a escolha desses produtos (PORTO,2009).

Essa pesquisa visa testar a eficácia das propagandas e preços das marcas classificadas com seus benefícios informativos, desde as mais até as menos conhecidas. E de seus impactos em relação aos tipos de produtos, pois além da diferença entre marcas, existem também as diferenças entre os produtos, ou seja, a venda de produtos essenciais não será necessariamente influenciada pelos mesmos aspectos que influenciarão a venda de produtos supérfluos.

\subsection{Formulação do problema}

Partindo da premissa de que a fatia de mercado é influenciada pelas estratégias de marketing, será avaliado como os produtos de alimentos essenciais e supérfluos com marcas de benefícios informativos diferentes se comportam diante das principais estratégias. Sendo assim, a pergunta de pesquisa é a seguinte: 
Será que as estratégias de marketing influenciam as fatias de mercado de forma diferenciada para marcas que oferecem benefícios informativos distintos tanto para produtos essenciais quanto supérfluos?

\subsection{Objetivo Geral}

Avaliar o impacto das estratégias de marketing na fatia de mercado, com o controle dos benefícios informativos das marcas em produtos essenciais e supérfluos.

\subsection{Objetivos Específicos}

- Analisar o impacto entre a quantidade de inserções de propaganda e preço médio das marcas na fatia de mercado em produtos alimentícios;

- Analisar a relação preditiva entre a disponibilização de propaganda em geral, folhetos promocionais, preço promocional, preço premium e preço concorrencial na fatia de mercado diária das marcas;

- Analisar a relação preditiva entre a disponibilização de propaganda em geral, folhetos promocionais, preço promocional, preço premium e preço concorrencial na fatia de mercado diária, com controle dos benefícios informativos das marcas em produtos essenciais e supérfluos.

\subsection{Justificativa}

Como conseqüência do impacto das estratégias de preço e propaganda estabelecidas pelas marcas pode-se obter o aumento ou a queda das fatias de mercado. Atualmente no setor de varejo, em especial no ramo de supermercados escolhido para realização da pesquisa, existem diversos tipos de estratégias, porém o conhecimento sobre seus resultados e impactos reais nas vendas dos produtos 
anunciados foi sendo adquirido com o passar do tempo e com a experiência dos funcionários tornando-se assim um conhecimento tácito.

Segundo Nonaka \& Takeuchi (1997), o conhecimento tácito é o conhecimento subjetivo; habilidades inerentes a uma pessoa; sistema de idéias, percepção e experiência; difícil de ser formalizado, transferido ou explicado a outra pessoa. Sendo assim, não se têm dados e análises precisas do impacto real das propagandas e descontos na venda das marcas e produtos anunciados e a relação entre o benefício informativo das marcas de produtos essenciais e supérfluos.

Diante do contexto acima, é comum o gestor de marketing ficar indeciso e sem o embasamento necessário para escolher qual produto/marca deve ser anunciado e/ou sofrer descontos para alcançar o aumento das vendas. Esse fato pode causar estagnação dos estilos de propagandas e bloquear a inovação com estratégias de propagandas e preço mais efetivas que envolvam um público ainda maior de pessoas podendo ser uma das justificativas para o fato de que o comércio varejista registrou queda de $3,0 \%$ no volume de vendas e alta de $0,3 \%$ na receita nominal em abril, na comparação com o mês anterior. Enquanto a receita nominal se manteve estável, o volume de vendas assinala resultado negativo após um trimestre de crescimento (IBGE,2010).

A mesma pesquisa citada acima apontou que hipermercados, supermercados, produtos alimentícios, bebidas e fumo, com variação de 5,6\%, teve a segunda maior contribuição (32\%) para a taxa global. Esses dados indicam que ações de marketing no setor varejista possuem grande impacto no mercado consumidor e por isso precisam ser bem estudadas e embasadas antes de serem aplicadas. Para isso é importante entender os principais fatores que motivam o consumidor e influenciam o seu poder de compra.

Neves e Cardoso (2008) afirmam que o consumidor desenvolve atitudes positivas e negativas em relação a produtos, pessoas e tudo o que diz respeito a sua própria vida. Tomando essa afirmação como verdadeira e considerando que não existem pessoas com motivações, atitudes e personalidades iguais, é necessário pensar em critérios e requisitos que possam fazer parte da nova estratégia, inovar e abarcar ainda mais o público-alvo que se quer atingir.

Para obter estratégias mais embasadas e confiáveis, faz-se necessário entender a visão do consumidor em relação a qualidade da marca e quanto ela é conhecida. Os consumidores geralmente buscam informações antes de comprar os 
produtos: eles procuram por bons preços, marcas específicas, boa qualidade dos produtos e até boas condições de pagamento (OLIVEIRA-CASTRO, 2003), o que comprova a importância de se pesquisar sobre a marca, o produto e suas relações com as quantidades vendidas.

Espera-se que com o resultado desse trabalho sejam criadas iniciativas de propaganda e precificação efetivas e que despertem ainda mais o interesse do consumidor a fim de eliminar os gastos com iniciativas que não geram o valor esperado pelos gerentes de marketing e reduzi-los com iniciativas que aumentarão a venda e conseqüentemente o faturamento da empresa. 


\section{REFERENCIAL TEÓRICO}

A fim de aprofundar os temas das áreas de pesquisa tratadas nesse projeto o referencial teórico foi classificado em três subtítulos: influência das estratégias de marketing: propaganda e preço, fatia de mercado e benefício simbólico alto e baixo das marcas.

\subsection{Influência das Estratégias de Marketing: Propaganda e Preço}

\section{Segundo Churchill e Petter marketing é:}

O processo de planejar e executar a concepção, estabelecimento de preços, promoção e distribuição de idéias, produtos e serviços a fim de criar trocas que satisfaçam metas individuais e organizacionais (CHURCHILL; PETER, 2000).

Filho e Lepsch (2004) afirmaram que nos últimos anos a comunicação de marketing tem desempenhado um papel de destaque no mix marketing, tornando-se uma ferramenta estratégica da empresa para se posicionar no mercado. A comunicação de marketing pode ser compreendida analisando-se os dois elementos que a compõe: a comunicação, que "é o processo pelo qual os pensamentos são transmitidos e o significado é compartilhado entre pessoas ou entre organizações e pessoas" e o marketing que dentre as inúmeras definições pode ser considerado como um meio das empresas transferirem valor entre elas ou entre seus clientes. (SHIMP, 2002)

Ambos os conceitos acima afirmam que o marketing possui um papel importante para o alcance das iniciativas estratégicas e de competitividade de mercado. Neves e Cardoso (2008) aplicaram uma pesquisa para analisar a atitude dos consumidores relativamente à marca dos distribuidores em Portugal e chegaram a conclusão de que a marca tem de ser capaz de transmitir ao consumidor as vantagens que este retira ao consumir o produto ou marca. Porém colocar esse conceito em prática tem se tornado ainda mais difícil uma vez que a cada dia que passa a concorrência do mercado aumenta e a diferenciação se torna uma tarefa mais dinâmica o que dificulta o estabelecimento de vantagens de um produto em relação ao outro. 
Uma marca para chegar até a fase do reconhecimento e ter uma imagem positiva no mercado deve ser composta por estratégias de marketing consistentes e bem sucedidas. De acordo com Casas (1994) preços são expressivos componentes do composto de marketing para a formação de imagem. Essa afirmação pode ser explicada por um dos resultados da pesquisa realizada por Musatti; Plens; Araújo; Berto (2002) que estudou a preferência do consumidor no mercado de produtos de serviço de consumo do auto-serviço brasileiro comparando marca e preço e concluiu que as marcas líderes de mercado no Brasil tiveram que se adaptar principalmente ao crescimento das marcas regionais, com redução do diferencial de qualidade percebido entre as duas, esforço de planejamento de marketing das regionais e $2^{a}$ linha, forçou as líderes a reavaliarem varias de suas estratégias de gerenciamento de produto, uma delas foi adotar preços mais competitivos e condizentes com a noção de valor do consumidor.

Muitos são os conceitos utilizados para definição de propaganda e preço. Sant' Anna (2000) definiu propaganda como "a arte de despertar no público o desejo de compra, levando-o à ação. (...) se a propaganda não levar à ação, a sua finalidade precípua, que é de estimular vendas, não terá valor".

Esclarecido o conceito de propaganda é o momento de relacioná-lo o às estratégias de preço. Segundo Botelho e Urdan (2005) o preço tem sido estudado sob várias perspectivas e níveis de intensidade principalmente pela economia, finanças, marketing e mesmo psicologia. Parece, entretanto, que, apesar de o marketing satisfazer melhor o critério pragmatismo em relação à economia no estudo do preço, a ciência do marketing tem contribuído muito pouco para a eficácia de apreçamento das empresas. Simon (1989) relata grande discrepância entre a teoria e a prática no estudo do preço, devido principalmente à negligência aos problemas de informação, quantificação e implementação de modelos teóricos de precificação. Morris e Morris (1994) partem do princípio de que a precificação de um produto deve levar em consideração que a principal tarefa do negócio é criar valor no mercado e que a função do preço é refletir o valor do produto.

Segundo Oliveira-Castro (2003), os consumidores procuram bons preços, marcas específicas, boa qualidade e até boas condições de pagamento na hora de escolher um produto. Esses quesitos levam a escolha pessoal de cada consumidor, Ehrenberg, Uncles e Goodhardt (2002) afirmaram que a maioria dos consumidores escolhe comprar uma marca mais freqüentemente que outra. 
Por outro lado, Smith e Park (1992) fizeram uma pesquisa e publicaram no Journal of Marketing Research que a fatia de mercado e a eficiência da publicidade aumentam quando o contexto é composto principalmente por experiências e atributos e compete em mercados onde os consumidores têm conhecimento limitado da classe de produto. Porém, com o resultado dessa pesquisa pode-se relatar que a quantidade de propagandas é um dos insumos que pode ser utilizado para avaliar a eficiência da publicidade.

Para Mankiw (2009), a lei da oferta e da demanda diz que o preço de qualquer bem ou serviço ajusta-se para trazer a quantidade demandada desse bem ao equilíbrio. A quantidade ofertada de um bem é positivamente relacionada com o preço, enquanto a quantidade demandada dele tem relação negativa com esse. Ou seja, quando a demanda por um produto for grande e sua oferta no mercado for pequena o preço tende a aumentar e vice e versa, quando a demanda for pequena e a oferta no mercado grande, o preço tende a diminuir. Nesse trabalho serão analisadas três estratégias de preço e seus impactos de acordo com a categorização dos produtos em essenciais e supérfluos e seus benefícios simbólicos, são elas: preço promocional, preço premium e preço em relação aos concorrentes.

Dominguez (2000), afirma que na maioria dos setores, os clientes mais leais estão dispostos a pagar (e pagam efetivamente) um preço premium em média $20 \%$ superior pela marca de sua preferência

\subsection{Fatia de Mercado de Produtos Essenciais e Supérfluos}

Segundo Cobra (2005), é necessário medir os resultados de vendas proporcionados pela promoção de vendas, pela propaganda, pelo merchandising, pelo marketing direto, pela ação de relações publicas e acessória de imprensa, entre outros esforços promocionais. Porém, para que exista a venda é necessário que antes sejam identificadas demandas. Na teoria essa relação entre a venda e a demanda parece simples, porém na prática nem sempre acontece e infelizmente produtos são colocados a venda no mercado sem que exista demanda suficiente para consumí-lo. 
A influência das estratégias de marketing, mais especificamente das estratégias que envolvem propaganda e preço que serão analisadas nesse trabalho, definem a fatia de mercado (market share) de cada marca. As vendas das marcas são determinadas por medidas como a quantidade de clientes que compram a marca, quantas vezes e quanto eles compram outras marcas (EHRENBERG, UNCLES, GOODHARDT, 2002). Sendo assim, é possível afirmar que a fatia de mercado é definida pelo somatório das compras da marca dividido pelo somatório de compras de todas as marcas da categoria.

Para Ehrenberg, Uncles e Goodhardt (2002) grandes e pequenas marcas se diferenciam significativamente em relação a quantidade de compradores que possuem, porém quando trata-se de quantidade de compradores fiéis essa relação é bem menor. Esse fato pode ser explicado por Mc.Carthy e Perreualt (1997), quando afirmam que um dos princípios essenciais que determina se uma marca será bem sucedida, é sua capacidade de atender as verdadeiras expectativas dos consumidores e de manter viva esta promessa - um verdadeiro contrato mercantil: De uma parte a empresa se compromete a sempre manter um padrão de satisfação constante para o consumidor e este se compromete em retribuir com a fidelidade. Cizinkota (2001) complementa dizendo que através do tempo as marcas criam a fidelidade que se escuda em sua reputação no mercado alvo e determina seu valor.

Resumindo, a marca tem de ser capaz de transmitir ao consumidor as vantagens que este retira ao consumir o produto ou marca, uma função cada vez mais difícil devido ao mercado cada vez mais homogeneizado e concorrente. A marca tem de mostrar ao consumir a sua superioridade em relação às restantes marcas no que diz respeito a sua qualidade (NEVES, CARDOSO, 2008).

Dentro do setor varejista de alimentos existe uma classificação que difere seus produtos em essenciais e supérfluos. Para Maluf (2000) existe uma estratificação do consumo de alimentos que leva à segmentação dos mercados segundo o valor agregado aos produtos através da diferenciação ou do maior grau de elaboração dos mesmos. Sendo assim, ele considera que os produtos essenciais são os menos elaborados e podem ser chamados também de produtos essenciais. Seguindo esse raciocínio podemos dizer que os produtos supérfluos ao contrário são os produtos melhor elaborados.

Leugi (2008) aplicou uma pesquisa acerca de critérios de compra de bens, processos de escolha, grau de satisfação acerca do modo de comprar, de local de 
compras rotineiras, intenção de mudança de qualquer critério influente em suas decisões de consumo e chegou conclusão representada pelos dados apresentados na tabela 1 que se encaixam com os produtos avaliados nesse projeto que são arroz e feijão para representar os produtos essenciais e iogurte e sorvete para representar os produtos supérfluos.

Tabela 1-Percentagem de participantes que indicaram os produtos com maiores índices como consumidos regularmente

\begin{tabular}{l|l|l|l}
\hline \multicolumn{1}{c|}{$100 \%$} & \multicolumn{1}{c|}{$91-99,9 \%$} & \multicolumn{1}{c}{$81-90,9 \%$} & \multicolumn{1}{c}{$80,9 \%$} \\
\hline Açúcar & Água sanitária & Absorvente & Batata \\
\hline Extrato de Tomate & Arroz & Alface & Chocolate em Pó \\
\hline Feijão & Bolacha & Alho & Desodorante \\
\hline Oléo & Café & Amaciante & Leite Condensado \\
\hline Papel Higiênico & Carne Bovina & Banana & Maçã \\
\hline Sabonete & Condicionados & Cebola & Refrigerante \\
\hline & Creme Dental & Farinha de Trigo & Rodo \\
\hline & Desinfetante & logurte Potinho & Shampoo \\
\hline & Escovas de Dentes & Leite Longa Vida & Suco de Fruta em Pó \\
\hline & Esponjas & Ovos & Tomate \\
\hline & Frango & Sabão em Pedra & Vassoura \\
\hline & Lingüiça & Salsicha & \\
\hline & Macarrão Comum & Vinagre & \\
\hline & Palha de Aço & & \\
\hline & Sabão em Pó & & \\
\hline & Sal & &
\end{tabular}

Através da análise pode-se observar que $91 \%$ a $100 \%$ dos participantes da pesquisa consomem rotineiramente os produtos classificados como essenciais que no caso são o arroz e o feijão. Já os supérfluos possuem percentagem de consumo rotineiro menor, o iogurte foi mencionado por $81 \%$ a $90 \%$ dos participantes enquanto o sorvete nem chegou a ser citado. Sendo assim, pode-se concluir que os produtos essenciais possuem consumo rotineiro maior do que os produtos classificados como supérfluos.

Na mesma pesquisa retratada acima, Leugi (2008) perguntou sobre a caracterização dos produtos que ele chamou de necessários e supérfluos. Praticamente todos os entrevistados relataram existir produtos necessários e supérfluos (somente dois disseram não haver essa diferenciação). Essa amostra apresentou o seguinte resultado: 
- Produtos Necessários/Essenciais: alimentos necessários, limpeza, higiene pessoal e vestuário;

- Produtos Supérfluos: alimentos supérfluos, produtos de limpeza substituíveis, produtos e/ou serviços de beleza e/ou perfumaria.

Segundo Pereira, Cabello e Gallo (2007) os produtos de extrema necessidade, como os da cesta-básica, podem ter até isenção de IPI (Imposto sobre Produtos Industrializados), enquanto produtos não considerados essenciais produtos essenciais possuem tributação mais elevada. Baleeiro (1997) complementa conceituando o que vem a ser essencialidade e porque as alíquotas do IPI são estabelecidas levando em consideração esse critério, para ele, a palavra (essencialidade) (...) refere-se à adequação do produto à vida do maior número dos habitantes do país. As mercadorias essenciais à existência civilizada deles devem ser tratadas mais suavemente ao passo que as maiores alíquotas devem ser reservadas aos produtos de consumo restrito, isto é, o supérfluo das classes de maior poder aquisitivo. Geralmente são os artigos mais raros e, por isso, mais caros.

De acordo com a classificação acima podemos concluir que os produtos essenciais são de fácil acesso e processo de produção quando comparados com os produtos supérfluos, além de representarem os produtos que satisfazem as necessidades básicas dos consumidores.

Essenciais e supérfluos são classificações referentes aos produtos em si, porém existem também as classificações das marcas que dentre outras podem ser consideradas marcas de benefício simbólico alto e marcas de benefício simbólico baixo.

\subsection{Benefício Simbólico Alto e Baixo das Marcas}

Segundo Farias (2005) os indivíduos escolhem contingências de trabalho individuais em que o reforço depende exclusivamente das respostas do organismo sendo, portanto, independente das respostas de outros, ou seja, pode-se dizer que na presença de uma marca que trouxe uma conseqüência reforçadora para o consumidor em ocasiões passadas, o próximo contato da pessoa com ela pode sinalizar uma probabilidade de que aquela conseqüência obtida anteriormente pode 
ser alcançada de novo (PORTO, 2009). Além do reforço especificado acima eles podem ser também nulos ocasionando a extinção das respostas e punitivos diminuindo as taxas dessas respostas.

Para Foxall $(1990,1997,1998)$ o Benefício Simbólico também conhecido como Reforço Informativo é social, mediado por outras pessoas, e está relacionado, por exemplo, ao nível de status social e prestígio obtido pelo consumidor, ao adquirir um produto ou serviço. Desse reforço informativo originou-se do modelo que ele mesmo Foxall $(1990,1997,1998)$ propôs, chamado Modelo da Perspectiva Comportamental (Behavior Perspective Model [BPM]), que analisa o comportamento do consumidor a partir da tríplice contingência: antecedente, resposta e conseqüência, ou seja, é utilizado para analisar a situação do consumidor e investigar por que e como consumidores escolhem marcas e produtos diferentes (ou similares) analisando a natureza dos conseqüentes (PORTO, 2009).

Uma conseqüência peculiar gerada pela relação entre os antecedentes e o comportamento dos consumidores é o fato de que normalmente eles passam pelas fases de reforço e punição simultaneamente. (FOXALL, 2006). Eles podem ser reforçados pelos benefícios provenientes de produtos e serviços, ou por meio de aprovação social, mas punidos, porque tem de renunciar reforçadores, tais como dinheiro e direitos, e de gastar tempo e esforço no processo de aquisição (ALHADEFF, 1982). O Modelo Perspectiva Comportamental (BPM) é uma estrutura operante para a interpretação do comportamento do consumidor que leva em conta essa peculiaridade, descrevendo o comportamento do consumidor como uma função das suas conseqüências e também antecedências.

No Brasil foi utilizado pelo Oliveira-Castro (2006) que o adaptou para a realidade do país a fim de facilitar ainda mais a questão dos efeitos informativos das conseqüências punitivas. Segue abaixo o Modelo da Perspectiva Comportamental adaptado por Oliveira-Castro, Foxall, James \& Cols (2006). 


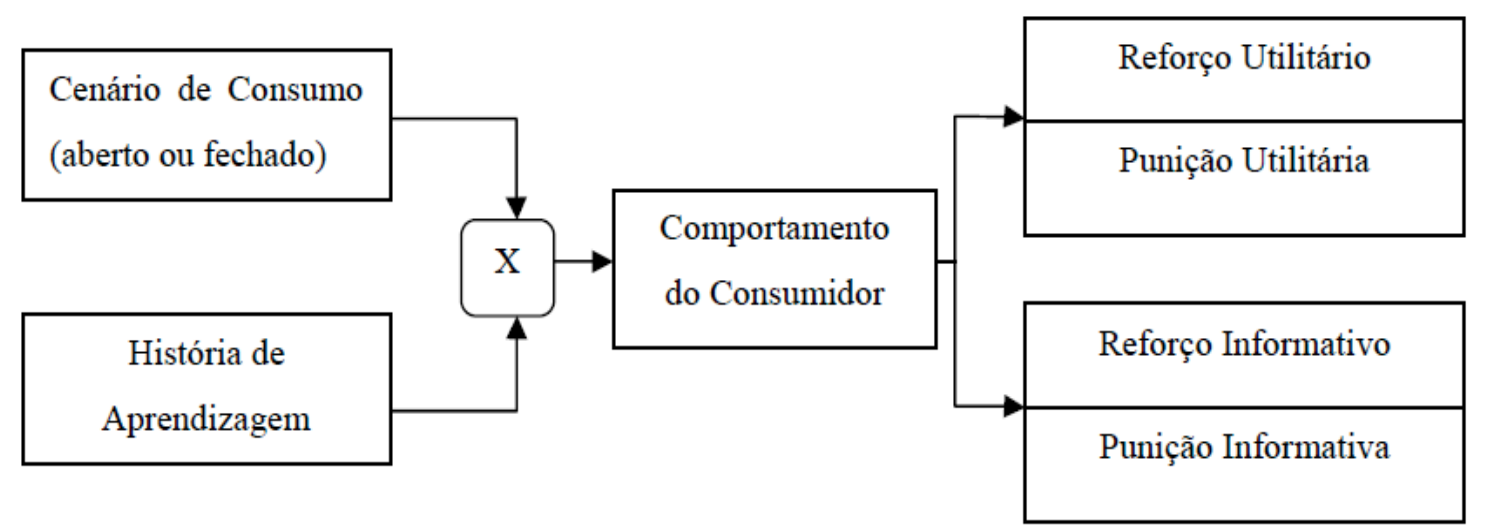

Figura 1 - Modelo Teórico de Foxall traduzido

Fonte: Oliveira-Castro, Foxall, James \& cols, 2006

O modelo propõe que o comportamento do consumidor seja determinado pela configuração de seu cenário de consumo e da história de aprendizagem de compra de um indivíduo. O cenário de consumo pode ser explicado como qualquer influência discriminativa capaz de gerar conseqüências, podendo ser estímulos físicos, sociais, temporais e regulatórios. Esses elementos juntamente com outros que possam surgir caracterizam o ambiente de compra.

Hoje os varejistas conhecem esses conceitos mesmo que seja apenas por experiências anteriores e já trabalham o ambiente de compra com o intuito de agradar cada vez mais o consumidor. De acordo com Foxall (1998) o escopo desse cenário pode ser um contínuo e varia entre ambiente relativamente fechado a relativamente aberto, sendo os critérios para diferenciar ambos:

- Número de estímulos discriminativos disponível,

- Quantidade de meios para obtenção dos reforços,

- Realização de tarefas específicas para obtenção de determinadas conseqüências,

- O consumidor ou outra pessoa deve controlar o acesso de conseqüentes,

- Contingencias são impostas por agentes que não irão desempenhar a tarefa;

- Existem alternativas acessíveis no ambiente para liberação de conseqüências

Resumindo os tópicos acima, pode-se dizer que o ambiente de consumo relativamente fechado tende a limitar possíveis comportamentos enquanto os ambientes de consumo relativamente abertos limitam menos e deixam o consumidor livre para demonstrar o seu comportamento.

Definido o cenário de consumo é o momento de abordar a aprendizagem onde são analisados efeitos de reforço e punição originados em outras ocasiões. 
Quando se identificam os estímulos ambientais que predizem e controlam a taxa de emissão do comportamento e suas relações conseqüentes, verifica-se uma relação chamada de contingencia (CATANIA, 1999). Essa relação faz referência a aprendizagem decorrente de experiências anteriores que acabam mudando de alguma forma o comportamento do consumidor. Sendo assim, pode-se dizer que cada indivíduo possui a sua própria aprendizagem de acordo com as variáveis encontradas durante suas experiências de compra.

Smith e Park (1992) publicaram uma pesquisa no Journal of Marketing Research que comprova a aprendizagem decorrente de experiências anteriores, segundo eles, a fatia de mercado e a eficiência da publicidade aumentam quando o as estratégias de marketing são compostas principalmente por experiências e atributos e competem em mercados onde os consumidores têm conhecimento limitado da classe de produto.

O reforço utilitário segundo Pohl e Oliveira Castro (2008) refere-se a benefícios derivados diretamente da posse e aplicação do produto ou serviço, são conseqüências medidas pelo produto ou serviço. Consiste nos resultados práticos da compra e do consumo, ou seja, benefício funcional, valor de uso e satisfação econômica, recebidos pelo consumidor na aquisição e uso do produto e serviço. Para Porto (2009) são resultados técnicos da compra e uso de produtos e serviços. Derivam do manuseio do produto ou do exercício do serviço. São conseqüências materiais ou pragmáticas da aquisição, posse, uso e consumo como um todo.

A pesquisa desse trabalho aborda o reforço informativo também conhecido como benefício simbólico, que será utilizado para avaliar o grau de conhecimento da marca e a qualidade percebida pelos consumidores. Segundo Pohl (2008) esse tipo de conseqüência é utilizado para passar feedback sobre o desempenho do indivíduo (valor da troca), e não na informação em si, resultando no nível de status social, prestígio e aceitação obtida pelo consumidor por adquirir o produto ou serviço. São informativas e simbólicas e derivam das ações e reações no relacionamento social (PORTO, 2009).

O resultado da pesquisa do benefício informativo fornecerá as marcas que serão classificadas no nível baixo, ou seja, as marcas pouco conhecidas e percebidas com baixa qualidade e as marcas que serão classificadas no nível Alto, ou seja, que são muito conhecidas e percebidas com alta qualidade. Sendo assim, pode-se concluir que o fato de conhecer o benefício simbólico das marcas pode criar 
uma vantagem competitiva para a área de marketing da organização uma vez que sabendo como você está perante seus concorrentes facilita a definição de seu posicionamento.

Em uma pesquisa aplicada por Porto (2009) para estabelecer a relação da variação das estratégias das marcas realizadas pelos lojistas sobre a fatia de mercado relativa, chegou-se a conclusão de que quanto maior for a variação das estratégias maior é a probabilidade de aumentar a fatia de mercado relativa da marca, sendo que a variação das estratégias é mais efetiva para aumentar a fatia de mercado das marcas de Benefício informativo alto.

Abib (2001) ressalta duas características que definem o valor: o efeito das conseqüências do comportamento sobre o próprio comportamento e o sentimento que acompanha esse efeito. Como para ele o efeito consiste no fortalecimento ou no enfraquecimento do comportamento, os sentimentos, polarizam-se, respectivamente, como positivos ou negativos. Conseqüências com efeitos fortalecedores e sentimentos positivos são boas e conseqüências com efeitos enfraquecedores e sentimentos negativos são más. Porto (2009) complementa dizendo que os estímulos que sinalizam a probabilidade de presença de reforço ou punição (conseqüências da relação estímulo-resposta) são chamados de estímulos discriminativos. Ou seja, quando uma pessoa possui uma experiência muito boa em algum lugar ela vai querer voltar ou vice e versa, quando ela passar por uma experiência traumática não terá vontade de voltar.

Em resumo, foi possível conhecer os melhores estudos, pesquisas e opiniões existentes no meio acadêmico sobre os temas de estratégias de marketing; vendas de produtos essenciais e supérfluos e benefícios simbólicos alto e baixo das marcas demonstrando que esse é um tema que está em ascensão e deve ser estudado principalmente no Brasil onde as referências teóricas ainda não são suficiente e as empresas que utilizam pesquisas como essas para aprimorarem seus modelos de gestão são raridades. 


\section{MÉTODOS E TÉCNICAS DE PESQUISA}

\subsection{Tipo e descrição geral da pesquisa}

Com o intuito de avaliar o impacto das estratégias de marketing na fatia de mercado das marcas de produtos essenciais e supérfluos com benefício simbólico alto e baixo, foi necessário aplicar uma pesquisa quase-experimental que aborda a necessidade de estudar o efeito de uma variável independente em ambientes em que não é possível alcançar o controle real dos recursos a serem estudados. (COZBY, 2009). Ou seja, nem sempre o pleno controle da aplicação dos estímulos experimentais ou a distribuição aleatória dos elementos que compõem os grupos são possíveis de se analisar, nesses casos é necessário aplicar a pesquisa quase experimental (Campbell, Stanley, 1979).

Segundo Kerlinger (1980), O propósito do investigador na realização de pesquisa quase experimental é tentar preparar um delineamento para o ambiente mais próximo do mundo real enquanto procura controlar, da melhor forma possível, alguns condicionantes que afetam a validade interna. A fim de delinear o ambiente nesse caso foram selecionadas as estratégias de propaganda e preço da marca para analisar o impacto de cada uma delas na fatia de mercado. Segue a o modelo empírico do trabalho utilizado para ilustrar essa relação:

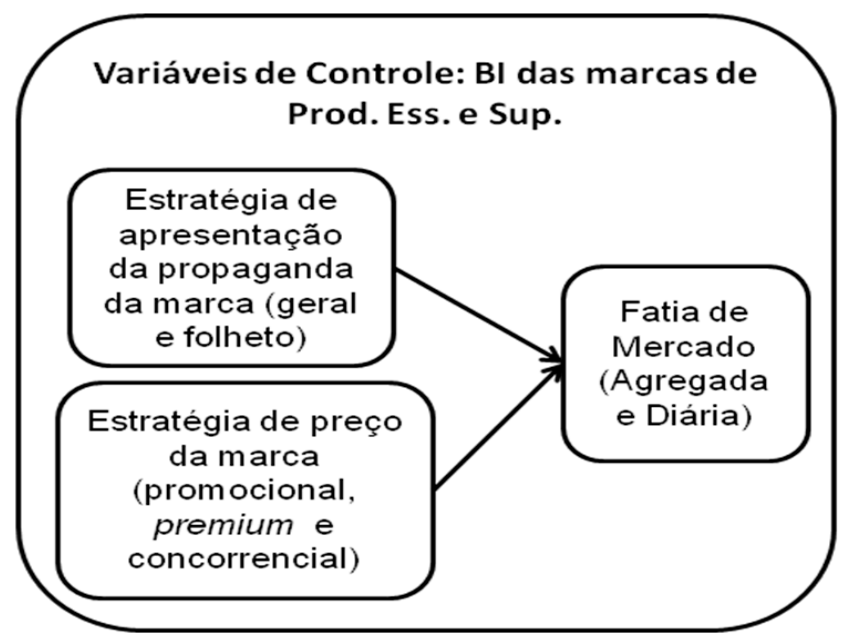

Figura 2 - Modelo Empírico do Trabalho 
Como é possível observar no modelo apresentado na Figura 2 a fatia de mercado foi analisada de duas formas pelas estratégias de marketing e preço da marca foram elas agregada e diária. Para cada uma utilizou-se um método de regressão, sendo regressão linear para a fatia de mercado agregada e regressão ordinal para a fatia de mercado diária.

\subsection{Caracterização da organização, setor ou área}

O foco desse trabalho é avaliar o impacto das estratégias de marketing na fatia de mercado, com o controle dos benefícios informativos das marcas em produtos essenciais e supérfluos, ou seja, não envolve estudos sobre o local forneceu os dados. Porém contextualizar o setor pode ajudar a entender a pesquisa e seus resultados, nesse caso o setor analisado foi o de varejo de alimentos.

De acordo com Santos e Costa (1997) trata-se de um setor onde a concorrência é crescente entre formatos idênticos, entre formatos diferentes e até mesmo entre fornecedores e varejistas, principalmente no caso de supermercados, no que diz respeito à disputa entre marcas de produtor e marcas de distribuidor.

Os dados de vendas dos produtos essenciais e supérfluos da pesquisa foram retirados de um supermercado que segundo William e Luiz Carlos (2000), caracteriza-se pela venda predominante de alimentos frescos ou mercearias e artigos de higiene e limpeza, apresentam alto giro e baixa margem, mantêm preços competitivos, trabalham com o conceito de auto-serviço e contemplam um mínimo de dois check-outs e uma área de vendas superior a $350 \mathrm{~m}^{2}$.

A loja estudada faz parte de uma rede que hoje possui 17 lojas em todo o Distrito Federal, tem mais de vinte e dois mil metros quadrados de área de venda e conta com aproximadamente 2.600 colaboradores diretos e indiretos, em média passam diariamente por toda a rede mais de quarenta mil clientes. É uma das empresas da região Centro Oeste no segmento de supermercados que mais investe em ações de publicidade, comunicação e marketing, juntamente com seus fornecedores a fim de obter maior visibilidade da marca e fortalecer a relação junto ao consumidor. 


\subsection{População e amostra}

A pesquisa contou com dados secundários e primários. Os dados secundários foram retirados dos Relatórios de Movimentação de Produtos de cada marca e os primários da aplicação de questionários para a população de consumidores da loja estudada, localizada em Brasília-DF e que segundo dados da Coletânea de Informações Socioeconômicas da Região Administrativa I - Brasília (CODEPLAN, 2007) 24,5\% das pessoas está entre 35 a 49 anos, $74,7 \%$ possui grau de instrução de $2^{\circ}$ grau completo a cima e a renda bruta média mensal domiciliar é de $\mathrm{R} \$ 5.026,00$. A pesquisa foi aplicada nas proximidades da loja e com clientes que moram na Asa Sul (Brasília - DF).

Para calcular o tamanho da amostra dos dados secundários de quantidade de dias necessários para que a pesquisa fosse generalizável, utilizou-se o teste estatístico $X^{2}$ (quiquadrado) necessário para adaptar o modelo à regressão ordinal. $A$ analise do quase experimento foi feita para cada subgrupo da amostra geral: (1) marcas com benefícios informativos baixos de produtos essenciais (508 dias), (2) marcas com benefícios informativos altos de produtos essenciais (537 dias), (3) marcas com benefícios informativos baixos de produtos supérfluos (264 dias) e (4) marcas com benefícios informativos altos de produtos supérfluos (247 dias).

Como a menor amostra foi de 247 dias de compra da marca, o cálculo do poder amostral foi realizado para este grupo a fim de verificar generalização e evitar o Erro Tipo 2. Sendo assim, pode-se perceber que o poder do teste para uma amostra de 247 dias é de $97 \%$, com $\chi 2$ crítico $=11,1$ e um tamanho de efeito médio $w=0,3$. 


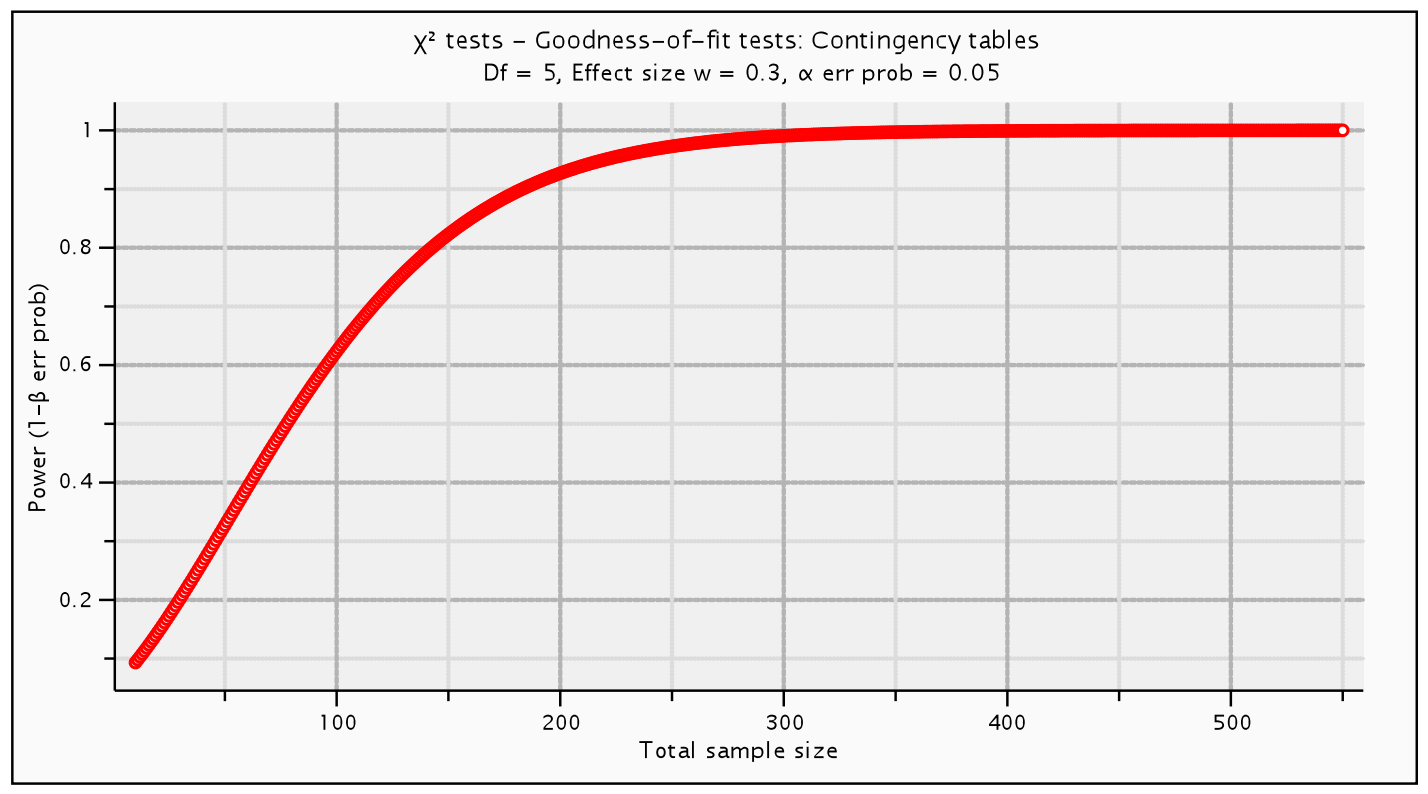

Figura 3 - Gráfico do Teste X²

Para a análise do benefício simbólico das marcas aplicou-se um questionário com os consumidores da loja, pois o fato de classificar as marcas entre Marcas de Benefícios Simbólicos Altos e Marcas de Benefícios Simbólicos Baixos ajuda a entender a percepção do cliente e os padrões de consumo de cada perfil de consumidor. O tamanho amostral nesse caso foi feito através de um teste estatístico chamado Análise de Variância (ANOVA) que pertence a família $F$, portanto é utilizado para determinar a significância das estatísticas. Para isso o cálculo a post hoc do poder da amostra com erro de probabilidade $\alpha=0,05$ com o tamanho do efeito igual a 0,4 (efeito grande) acusou poder amostral de $81 \%$ para o produto que tem maior quantidade de marcas (arroz com 9 marcas, feijão com 7 marcas, iogurte com 4 marcas e sorvete com 5 marcas).

O resultado sugeriu um $\mathrm{F}$ crítico de 3,96 e tamanho da amostra de 84 pessoas. Sendo assim, foram aplicados 100 questionários, ou seja, 100 pessoas responderam como elas visualizam cada marca em relação ao seu conhecimento e ao seu nível de qualidade percebida e conclui-se que a amostra utilizada foi além da necessária para obter resultados generalizáveis. 


\subsection{Caracterização dos instrumentos de pesquisa}

O questionário aplicado para análise do benefício simbólico das marcas foi validado por Pohl e Oliveira-Castro (2008) e adaptado por Porto (2009). As marcas contempladas foram separadas por produto e contou com o entrevistado para marcar quanto ele julga que a marca em questão é conhecida e como ele avalia o seu nível de qualidade, pois nem sempre a que é mais conhecida é a de melhor qualidade e vice e versa. Ao todo foram avaliadas 9 marcas de arroz, 7 marcas de feijão, 4 marcas de iogurte e 5 marcas de sorvete.

O nível informativo utilizou uma escala de 0 a 3 para avaliar o grau de conhecimento da marca e a qualidade percebida pelo consumidor. No caso do grau de conhecimento da marca a escala teve o seguinte significado: 0 é desconhecida, 1 pouco conhecida, 2 medianamente conhecida e 3 muito conhecida. No caso da qualidade percebida pelo consumidor a escala foi: 0 é sem opinião, 1 baixa qualidade, 2 média qualidade e 3 Alta qualidade, sendo que se o consumidor marcou 0 na qualidade percebida ele foi retirado da análise.

Os dados foram compilados a fim de descobrir o efeito de interação já que marcas muito conhecidas e percebidas como de pouca qualidade não são iguais as marcas muito conhecidas e percebidas como de alta qualidade (PORTO, 2009). A partir dessas informações realizou-se um teste para classificar as marcas nos dois níveis informativos. Segundo Pohl (2004) o nível informativo baixo deve ser representado pelas marcas pouco conhecidas e percebidas com baixa qualidade e 0 nível informativo alto deve ser representado pelas marcas muito conhecidas e percebidas com alta qualidade.

Além da aplicação dos questionários, foi realizada uma análise documental dos relatórios de movimentação dos produtos para compreender o que significava cada campo e quais os tipos de informações que poderiam ser retirados para o cálculo do impacto das estratégias de marketing na fatia de mercado, com o controle dos benefícios informativos das marcas em produtos essenciais e supérfluos. Através desses instrumentos foi possível coletar e analisar os dados da forma descrita no tópico 3.5 (Procedimentos de coleta e de análise de dados). 


\subsection{Variáveis analisadas}

Algumas variáveis precisaram ser transformadas para que todos os produtos e marcas diferentes pudessem ser comparados e atendessem os pressupostos da análise multivariada. Na análise dos dados agregados cada variável foi transformada para avaliar todas as marcas do mesmo produto em uma só equação. Foram elas:

- Variável dependente:

- Fatia de mercado agregada de venda relativa ao produto: fatia de mercado da marca em todos os dias dividido pela media da fatia de mercado do produto em todos os dias.

- Variáveis independentes:

- Quantidade de propaganda relativa média do produto: quantidade de propaganda total da marca dividido pela quantidade média de propaganda do produto;

- Preço médio $(\mathrm{R} \$)$ : valor médio em todos os dias de cada marca.

$\mathrm{Na}$ análise com os dados diários, algumas variáveis precisaram ser transformadas em variáveis ordinais para atender a regressão ordinal:

- Variável dependente:

- Fatia de mercado diária relativa à média da marca ordinal: fatia de mercado da marca em cada dia dividido pela média da fatia da marca em todos os dias. Após esse cálculo a variável foi transformada em ordinal, baseada nos valores dos quartis.

- Variáveis independentes:

- Log do preço promocional: logaritmo do preço da marca no dia dividido pelo preço médio da marca em todos os dias;

- Log do preço premium: logaritmo do preço da marca no dia dividido pelo preço médio do produto em todos os dias;

- Log do preço concorrencial: logaritmo do preço da marca no dia dividido pelo preço médio do produto nesse dia;

- Apresentação de propaganda (geral): dicotômico. Sendo 0 = não teve propaganda da marca no dia e 1 = teve propaganda da marca no dia; 
○ Apresentação de propaganda (folheto): dicotômico. Sendo $0=$ não teve propaganda folheto da marca no dia e $1=$ teve propaganda folheto da marca no dia;

- Variáveis de controle quase - experimental:

- Nível informativo da marca: dicotômico. Sendo $0=$ marcas que apresentaram baixa média de conhecimento e percepção de qualidade e $1=$ marcas que apresentaram alta média de conhecimento e percepção de qualidade;

- Produtos essenciais e supérfluos: dicotômico. Sendo $0=$ produtos essenciais e 1 = produtos supérfluos.

\subsection{Procedimentos de coleta e de análise de dados}

O projeto contou com a análise de dados secundários retirados dos Relatórios de Movimentação de Produtos do supermercado relativos ao período de 01 de janeiro de 2010 a 20 de abril de 2010 para avaliar a quantidade de vendas diária, planilhas de anúncios de folhetos e planilhas de anúncios gerais. E com a análise de dados primários extraídos da aplicação do questionário com consumidores dos produtos selecionados para descobrir quais são as marcas de maior e menor valor para o consumidor e avaliar o benefício simbólico das marcas.

Segue abaixo um modelo criado para resumir os procedimentos de coleta e análise de dados.

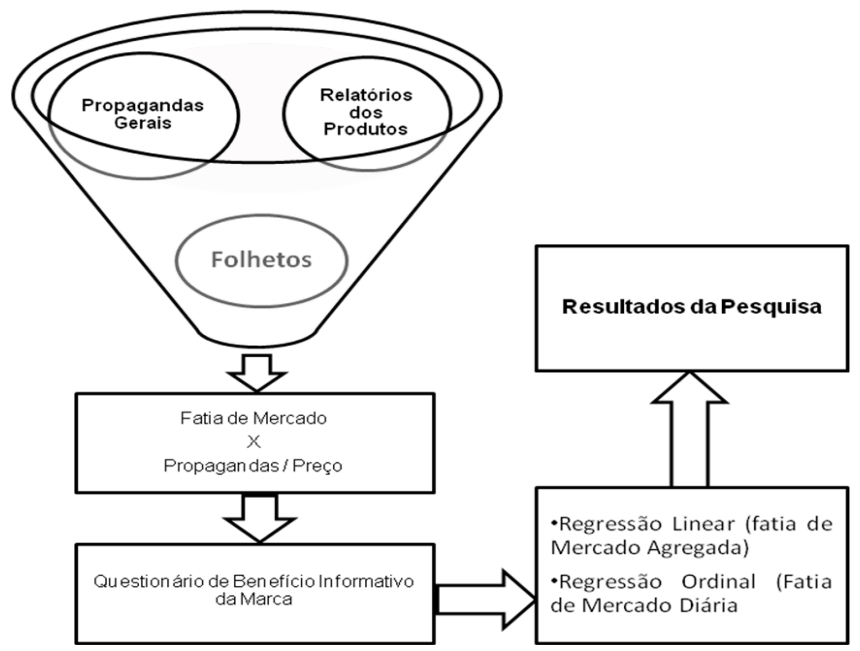

Figura 4 - Esquema de Procedimento de Coleta e Análise de Dados. 
Os dados obtidos através do Relatório de Movimentação Diário extraídos de cada marca dos produtos selecionados foram dos seguintes produtos: Arroz tipo 1 $5 \mathrm{Kg}$ e Feijão Carioca $1 \mathrm{Kg}$ (produtos essenciais) e logurte de Chocolate e Sorvete de Flocos (produtos supérfluos). Esse relatório é atualizado a partir do momento em que o funcionário do supermercado lança a informação no sistema e o produto é vendido para o consumidor. Já as informações sobre as propagandas gerais foram retiradas de uma tabela em Excel que contempla produtos que foram anunciados no período e se foi anunciado em folheto ou não.

De acordo com a Figura 4 para estabelecer os resultados relacionados a fatia de mercado agregada foi necessário aplicar a regressão linear, enquanto que para estabelecer os resultados relacionados a fatia de mercado desagregada, ou seja, diária foi utilizada a regressão ordinal. Segundo Malhotra (2004) a análise de regressão é o procedimento estatístico utilizado para analisar relações associativas entre uma variável dependente e uma ou mais variáveis independentes.

A regressão Linear aplica a seguinte fórmula $(y=a+b x+c z)$, onde "y" é igual a quantidade vendida diariamente, "a", "b" e "c" são parâmetros estatísticos utilizados para encontrar a equação de previsão de valor dos dados de venda (y) fornecidos através da análise de regressão estatística aplicada, " $x$ " é a variação da propaganda e "z" é a variação do preço. De acordo com a fórmula, quanto maior for a variação da propaganda e do preço maior será a variação da quantidade vendida.

Além da regressão linear, foi realizada também a regressão ordinal para possibilitar a análise diária dos dados respeitando sua ordem no tempo. O modelo logístico ordinal é um dos muitos modelos agrupados sob o contexto de modelos lineares generalizados para dados ordinais. O modelo logístico ordinal é baseado na suposição de que existe uma variável latente contínua em evolução e que o resultado observado ordinal surge categorização dos grupos adjacentes.

A fórmula da regressão ordinal é link $(g i j)=\theta j-[\beta 1 x i 1+\beta 2 x i 2+\ldots+\beta p x i J]$, onde link é a função, gij é a probabilidade acumulada da categoria nesse caso, qj é $p$ limite da categoria, $\mathrm{p}$ é o número de coeficientes de regressão, Xi1 e Xi2 são os valores dos preditores e finalmente $\beta 1$ e $\beta p$ são os coeficientes de regressão. Para calcular as análises diárias, O SPSS Ordinal possui um processo de regressão conhecido como PLUM (Ploytomous Universal Model), que é uma extensão do modelo linear geral para dados ordinais categorizados.em que se pode especificar 
cinco links de funções, bem como parâmetros de dimensionamento. O link utilizado foi o logit, portanto sua função foi $\ln (\mu \backslash 1-\mu)$, onde In é o log natural e corresponde ao que chamamos de $\mathrm{Y}$ na regressão linear. Segue a tabela 2 representando os cálculos da regressão ordinal:

Tabela 2 - Tabela Explicativa dos Cálculos de Regressão Linear de Benefício Simbólico das Marcas

\begin{tabular}{|c|c|c|}
\hline Benefício Simbólico & Produtos Sunérfluos & Produtos Fssenciais \\
\hline das Marcas & Proautos supertiuos & Proautos Essenclals \\
\hline Alto & $\operatorname{link}(g i j)=\theta j-[\beta 1 x i 1+\beta 2 x i 2+\ldots+\beta p x i J$ & $\operatorname{link}(g i j)=\theta j-[\beta 1 x i 1+\beta 2 x i 2+\ldots+\beta p x i J$ \\
\hline Baixo & $\operatorname{link}(g i j)=\theta j-[\beta 1 x i 1+\beta 2 x i 2+\ldots+\beta p x i J$ & $\operatorname{link}(g i j)=\theta j-[\beta 1 x i 1+\beta 2 x i 2+\ldots+\beta p x i J$ \\
\hline
\end{tabular}

Com a análise agregada espera-se que resultados gerais sejam identificados e impactem na maior parte dos produtos. Enquanto com a análise diária pretende-se encontrar resultados mais aprofundados e conseqüentemente as causas de algumas observações visualizadas nos modelos de resultados agregados.

Para melhor entendimento dos resultados descritos na fase de resultados e discussão é importante alinhar o conceito estatístico de $r^{2}$. Stevenson (2000 apud PAIVA, 2005) explica que para medir a correlação entre as variáveis, pode ser utilizada a função RQUAD, conhecida como coeficiente de determinação $r^{2}$ ou o quadrado do coeficiente de correlação momento-produto "r" de Pearson. Refere que valores de $r=0$ significam ausência de relacionamento e $r=1$ (positivo ou negativo) demonstra um relacionamento perfeito. Ainda segundo o autor, um $r=0,70\left(r^{2}\right.$ de aproximadamente 0,49 ) aufere uma relação moderada. Esclarecido esse conceito, seguimos para etapa de resultados e discussão.

\subsubsection{Procedimento para Identificação da Influência das Estratégias de Propaganda e Preço na Participação de Mercado}

A partir do momento em que foi estabelecido o primeiro contato e os representantes do supermercado aprovaram a pesquisa fez-se necessário realizar três visitas ao local. A primeira teve como objetivo conhecer os gerentes das áreas, comercial e Marketing, para entender os seus Relatórios de Movimentação de Produtos e como funcionam as atuais formas de propaganda e desconto da empresa, além de selecionar junto com eles os produtos que foram estudados. A segunda visita possibilitou a coleta dos dados de vendas diários de cada marca dos 
seguintes produtos: arroz, feijão, iogurte e sorvete e o entendimento do fluxo de processos realizados para alimentar o sistema de controle de vendas utilizado para gerar os relatórios de análise entregues. Já a terceira visita, ocorreu para esclarecer as dúvidas que surgiram durante o tratamento dos dados dos relatórios e as informações repassadas.

Com os dados secundários em mãos, foi necessário organizá-los na ferramenta Excel de forma a compilar todos os relatórios e informações de propagandas e anúncios em uma só planilha, calcular os campos de fatia de mercado total da venda e fatia de mercado total da venda relativa ao produto e estabelecer códigos para cada produto, marca e tipo (essenciais ou supérfluos). Após a compilação, todos os dados dessa planilha foram importados para o software SPPS (Statistical Package for the Social Sciences) que por sua vez, utilizou suas funcionalidades para gerar gráficos com significância que demonstraram, por exemplo, a relação entre a fatia de mercado agregado da venda e a quantidade de propaganda relativa ao produto dentre outros que serão apresentados na etapa de resultados e discussão.

Os dados agregados da pesquisa relativos a todas as marcas estudadas são utilizados para gerar respostas amplas e de maior interesse corporativo. Para isso, os valores aplicados foram a média das informações diárias de cada marca comparada com a média desses valores de cada produto. Sendo assim, para análise dos gráficos deve ser realizada a seguinte interpretação: se uma observação estiver sobre o valor 1 significa que ela está exatamente na média de todas outras, se estiver acima de 1 ela estará acima da média e se estiver abaixo de 1 estará abaixo da média. Ou seja, uma observação que esteja situada sob a linha 1,5 significa que ela está 0,5 acima da média das demais observações.

Para definição dos benefícios informativos das marcas e análises de suas relações com as vendas de produtos essenciais e supérfluos aplicou-se um questionário que será detalhado explicado no item 3.6.2. 


\subsubsection{Procedimento para Identificação do Reforço Informativo da Marca}

No mesmo período em que as análises das estratégias de marketing e seu impacto na participação de mercado de cada marca estavam sendo trabalhadas sentiu-se a necessidade de aplicar um questionário para classificação das marcas de benefício informativo alto e baixo de cada produto estudado e como já foi dito, para isso a técnica estatística de Análise da Variância, ANOVA, foi utilizada, afinal, trata-se de uma análise de regressão múltipla em que as variáveis independentes foram: preço médio e quantidade de propagandas relativas média do produto e a variável dependente foi: fatia de mercado agregada de venda relativa ao produto.

Para melhor confiabilidade dos dados foi utilizada a mesma metodologia aplicada por Porto (2009) em sua tese. Após o teste da Análise de Variância, as médias das marcas foram relacionadas com as fatias de mercado, adaptando as classificações dos níveis informativos com as amostras dos estímulos observados. Assim, as médias foram comparadas com as fatias de mercado para adequar o tamanho da amostra dos níveis informativos 1(baixo) e 2 (alto), pois poderia ocorrer de poucas marcas serem compradas de um nível ou de outro. Logo, quando um dos níveis ficou próximo a $50 \%$ (do total comprado) houve o corte dos níveis. Dessa forma, o nível informativo 1 representa as marcas menos conhecidas e/ou percebidas com baixa qualidade que, ao todo,representa cerca de $50 \%$ das compras totais. A mesma lógica seria para as marcas de nível informativo 2 que são as marcas mais conhecidas e/ou percebidas com alta qualidade que, ao todo, representa cerca de $50 \%$ das compras totais (PORTO, 2009).

Após a classificação de todas as marcas essa informação foi transferida para a mesma planilha de Excel e logo após importada para o SPSS que utilizou essa informação para o estabelecimento da análise de regressão ordinal. O próximo tópico apresenta os resultados e discussões gerados por essas análises. 


\section{RESULTADOS E DISCUSSÃO}

Para um melhor entendimento dos resultados e discussões apresentados nesse item, este foi dividido em três partes. Sendo a primeira parte, a influência das estratégias de propaganda e preço na fatia agregada de mercado, a segunda parte a influência das estratégias de propaganda e preço na fatia diária de mercado e a terceira e última parte a influencia das estratégias de propaganda e preço na fatia diária de mercado com controle dos benefícios informativos em produtos essenciais e supérfluos. A unidade de análise dos dados da primeira é agregada por marcas já as unidades da segunda e da terceira são diárias.

\subsection{Influência das Estratégias de Propaganda e Preço na Fatia Agregada de Mercado}

Inicialmente será apresentada a relação entre a variável dependente "fatia de mercado agregada de venda relativa ao produto" e a variável independente "quantidade de propaganda relativa média do produto".

Tabela 3 - Estimativas do Modelo

\begin{tabular}{c|c|c|c|c|c|c|c}
\hline \multirow{2}{*}{ Equação } & \multicolumn{5}{|c|}{ Modelo Resumo } & \multicolumn{2}{c}{ Parâmetros Estimados } \\
\cline { 2 - 8 } & $\mathrm{R}^{2}$ & $\mathrm{~F}$ & $\mathrm{Df1}$ & $\mathrm{Df2}$ & Sig. & Constante & $\mathrm{B} 1$ \\
\hline Linear & 0,83 & 100,40 & 1,00 & 21,00 & 0,00 & $-0,35$ & 1,37 \\
\hline
\end{tabular}

Variável independente: quantidade de propaganda relativa média do produto

O resultado da análise de regressão da Tabela 3 de Estimativas do Modelo demonstra que quanto maior for a variável independente "quantidade de propaganda relativa média do produto" $(B=1,37 ; p<0,01)$ maior será a fatia de mercado total de venda relativa ao produto. Através dela é possível dizer que a quantidade de propaganda relativa média do produto possui alto grau de relevância com a variável dependente fatia de mercado total de venda relativa ao produto, com $\mathrm{R}^{2}$ igual a aproximadamente $83 \%$.

O gráfico 1 evidencia a quantidade de propaganda relativa média do produto comparada com a fatia de mercado total relativa ao produto, o que torna possível vislumbrar as correlações entre essas variáveis. 


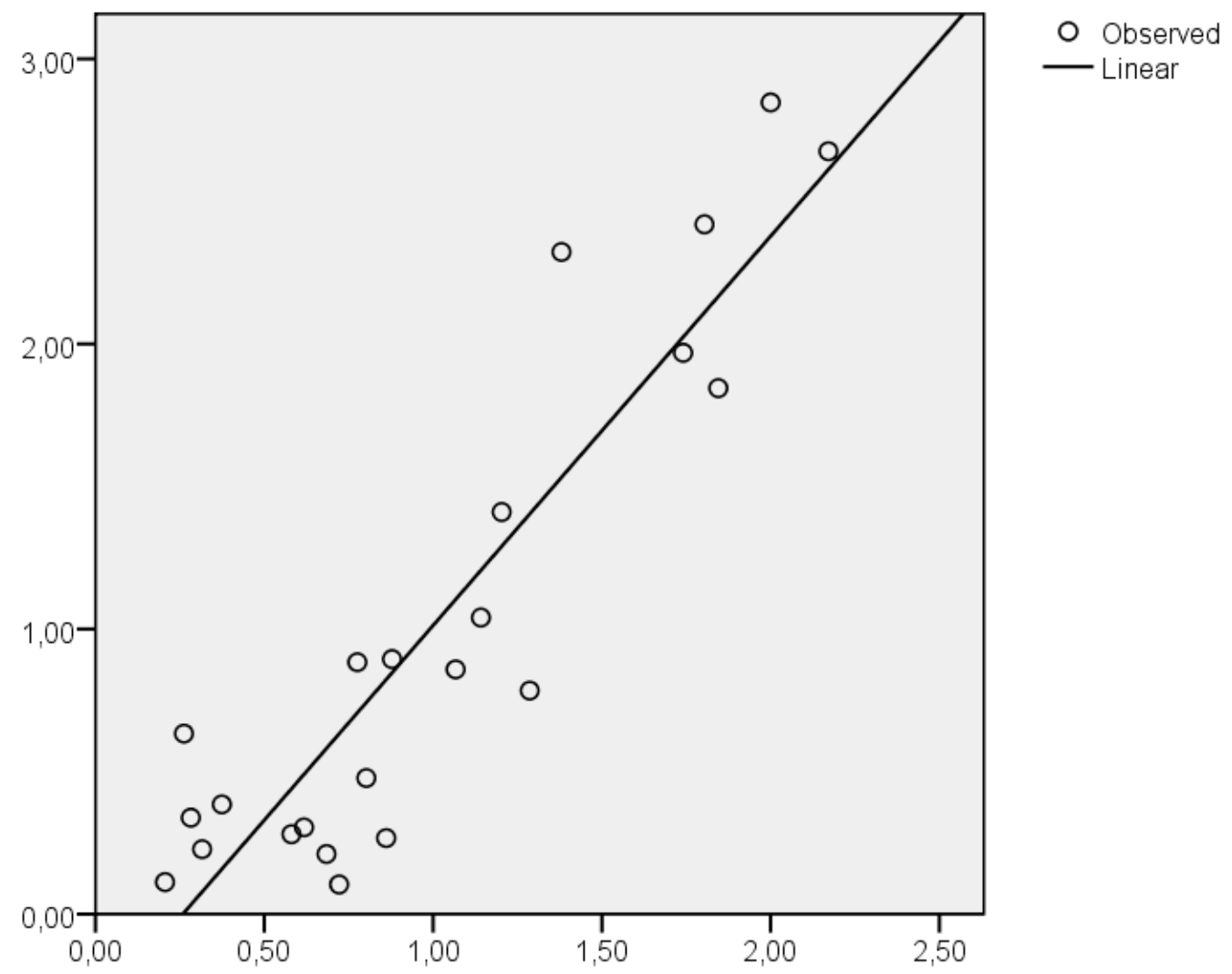

Figura 5 - Fatia de Mercado Agregada de Venda Relativa ao Produto X Quantidade de Propaganda Relativa Média do Produto

De acordo com o gráfico podemos dizer que reta da equação linear aplicada cuja constante é - 0,353 estabelece relação com as marcas dos produtos analisados. A maior parte das marcas de produtos estudados realiza pouca propaganda e conseqüentemente possui pequena participação de mercado com exceção de algumas marcas que provavelmente são as líderes de mercado de cada produto que estão 1,5 acima da média de quantidade de propaganda relativa média do produto e conseqüentemente, estão também 1,5 acima da média da fatia de mercado total de venda relativa ao produto. Sendo assim podemos dizer que a quantidade de propagada tem alto grau de influencia positiva na fatia de mercado.

Esse resultado complementa a pesquisa realizada por Smith e Park (1992) que afirma que apesar de não tratarem especificamente sobre a quantidade de propagandas abordam o tema de eficiência da publicidade, onde afirmam que a fatia de mercado e a eficiência da publicidade aumentam quando as estratégias de marketing são compostas principalmente por experiências e atributos e competem em mercados onde os consumidores têm conhecimento limitado da classe de produto. 
Além da quantidade de propaganda relativa média do produto, o preço médio, também foi utilizado como variável independente da variável dependente de fatia de mercado agregada de venda relativa ao produto.

Tabela 4 - Estimativas do Modelo

\begin{tabular}{c|c|c|c|c|c|c|c}
\hline \multirow{2}{*}{ Equação } & \multicolumn{5}{|c|}{ Modelo Resumo } & \multicolumn{2}{c}{ Parâmetros Estimados } \\
\cline { 2 - 8 } & $\mathrm{R}^{2}$ & $\mathrm{~F}$ & $\mathrm{Df} 1$ & $\mathrm{Df} 2$ & Sig. & Constante & $\mathrm{B} 1$ \\
\hline Linear & 0,00 & 0,04 & 1,00 & 22,00 & 0,84 & 0,94 & 0,01 \\
\hline Variável independente: preço médio
\end{tabular}

Variável independente: preço médio

O resultado da análise de regressão da tabela 4 de Estimativas do Modelo demonstra que a variável "preço médio" pode não ser preditora da variável dependente "fatia de mercado agregada relativa ao produto". Especificamente, o grau do nível de significância é 0,84 ou seja, maior que 0,05 e o coeficiente de determinação $R^{2}$ é igual a 0,002 , em outras palavras, apenas $0,2 \%$ da fatia de mercado total relativa ao produto pode ser explicada pela relação linear do valores. Sendo assim, a variável independente do preço médio não interfere de forma significativa na variável dependente fatia de mercado total relativa ao produto.

O gráfico da figura 6 evidencia a informação descrita acima. De acordo com ele a reta da equação linear aplicada cuja constante é 0,944 não estabelece uma relação com as marcas dos produtos observados. A maior parte das marcas está abaixo da reta e mesmo uma marca com valor médio maior que $R \$ 12,50$ possui fatia de mercado agregada relativa ao produto menor que 1 , ou seja, abaixo da média de mercado e outra marca, também com valor médio maior que $R \$ 12,50$ possui fatia de mercado total relativa ao produto maior que 1,5, ou seja, acima da média de mercado. $\mathrm{O}$ mesmo acontece com os produtos mais baratos de valor médio igual a $R \$ 2,50$ que podem representar fatias de mercado totais relativas ao produto abaixo de 0,5 e acima de 2,5.

Sendo assim, ao contrário do que Oliveira-Castro (2003) defende quando afirma que os consumidores geralmente buscam informações antes de comprar os produtos como bons preços, marcas específicas e boa qualidade, a fatia de mercado agregada de um produto não foi influenciada de forma significativa pelo preço médio, existem outras variáveis mais importantes que o preço nesse contexto. 


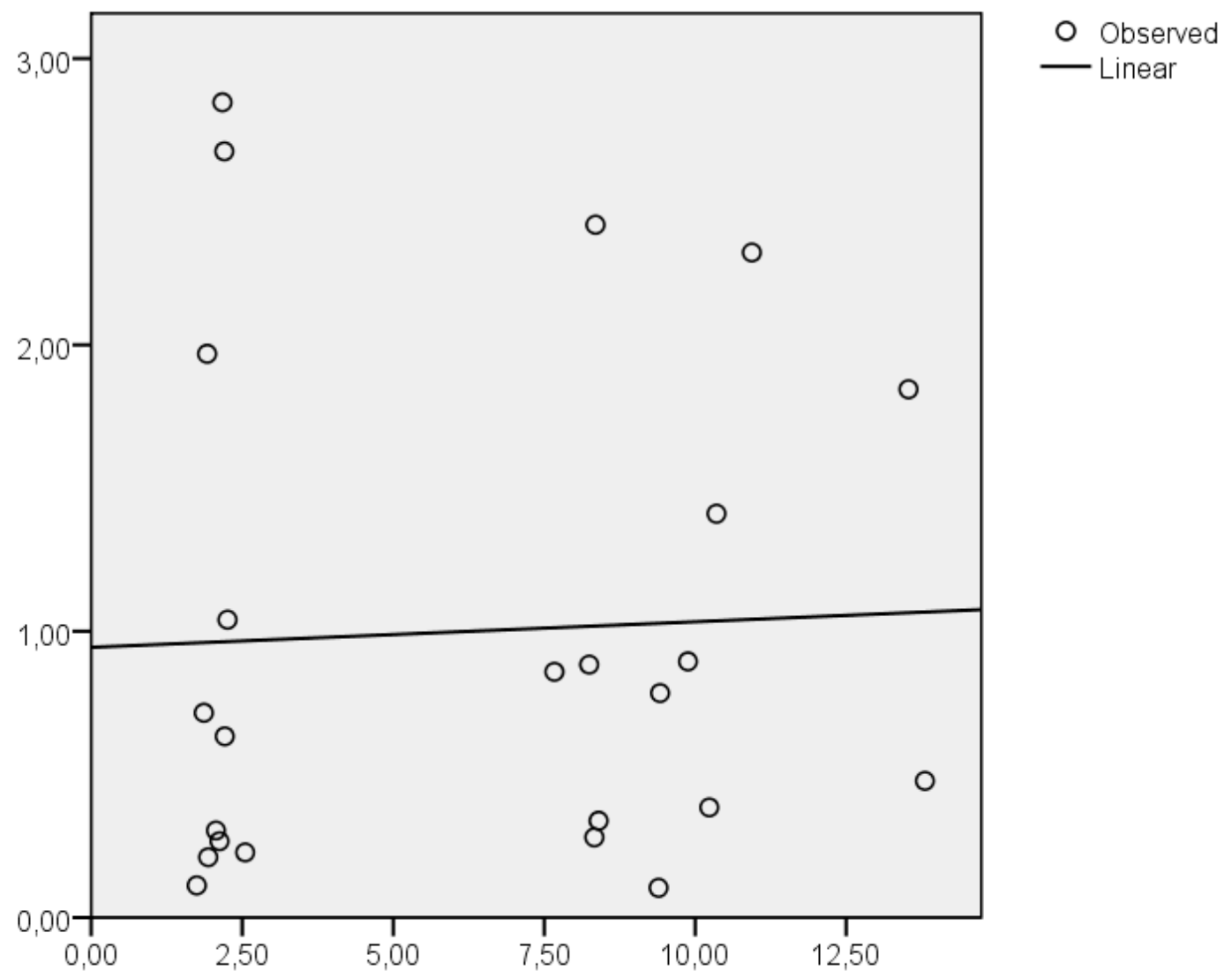

Figura 6 - Gráfico de Fatia de Mercado Total de Venda Relativa ao Produto X Preço Médio (R\$)

De acordo com os resultados apresentados nos gráficos desse item a influência das estratégias de propaganda e preço na fatia de mercado não segue o mesmo padrão. Como era de se esperar constatou-se que a quantidade de propaganda é um ponto extremamente relevante e significativo em relação a fatia de mercado e quanto maior for a quantidade de propaganda de um produto maior será sua fatia de mercado, porém talvez por ser algo caro, muitas marcas ainda não aumentaram sua fatia de mercado por não poder aumentar sua quantidade de propagandas. Por outro lado o preço aqui representado pelo valor médio em reais não demonstrou relação com a fatia de mercado. Sendo assim, levando em consideração apenas os resultados acima, uma empresa terá sucesso se aumentar a quantidade de anúncios e o preço do seu produto, pois assim aumentará sua fatia de mercado de venda.

Esses foram os resultados gerados pelos dados compilados de todas as datas e produtos realizados. O próximo tópico descreverá as análises dos dados com um enfoque diário. 


\subsection{Influência das Estratégias de Propaganda e Preço na Fatia Diária de Mercado com Controle dos Benefícios Informativos em Produtos Essenciais e Supérfluos}

Com o objetivo principal de avaliar o impacto das estratégias de marketing na fatia de mercado das marcas de produtos essenciais e supérfluos com benefício simbólico alto e baixo chegou o momento de relacionar os resultados diários.

Para ilustrar a variação da variável dependente da fatia de mercado diária para o controle quase experimental foram feitos gráficos temporais como o que está sendo representado pela figura 7 que analisa a relação entre a fatia diária de mercado de todas as 25 marcas estudadas e a fatia de mercado média por marca diariamente.

A figura 7 possibilita uma visão global de como foi a efetividade diária das estratégias de marketing representada pelos resultados da fatia de mercado dos produtos pesquisados. O gráfico aponta um destaque bem representado no dia 01/02/2010 e logo após um pouco menor no dia 12/02, porém apenas visualizando esses dados não é possível tirar informações conclusivas sobre o porquê desses comportamentos. Para isso foram gerados os gráficos que por tipo de produto (essenciais e supérfluos) e por benefício informativo da marca.

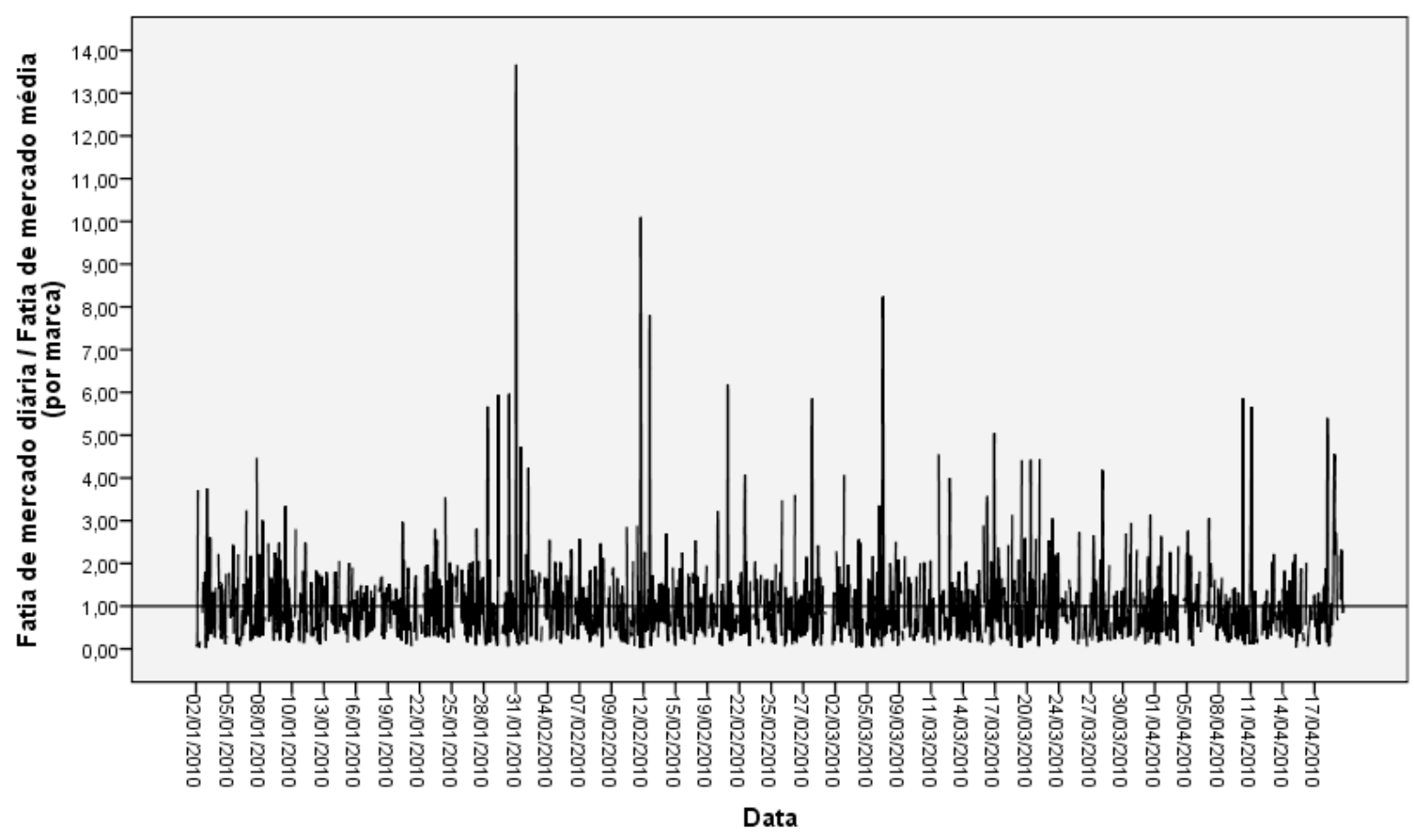

Figura 7 - Gráfico de Fatia de Mercado Diária / Fatia de mercado Média (por marca) 
Dando início a essa análise o primeiro gráfico a ser apresentado consiste na visualização da variação da variável dependente fatia diária da marca dos produtos essenciais (arroz e feijão) de nível informativo baixo.

A Figura 8 esclarece que a discrepância do gráfico anterior relacionado ao dia 01/02/2010 trata-se de um produto essencial que pode ser tanto o arroz quanto o feijão de uma marca de benefício informativo baixo. Segundo Urban, Carter e Gaskin (1986) uma análise empírica indica que a ordem de entrada da marca em uma categoria de produto de consumo é inversamente proporcional à sua fatia de mercado, sendo assim é possível dizer que apesar de ser uma marca de benefício informativo baixo provavelmente é uma marca já tradicional no mercado.

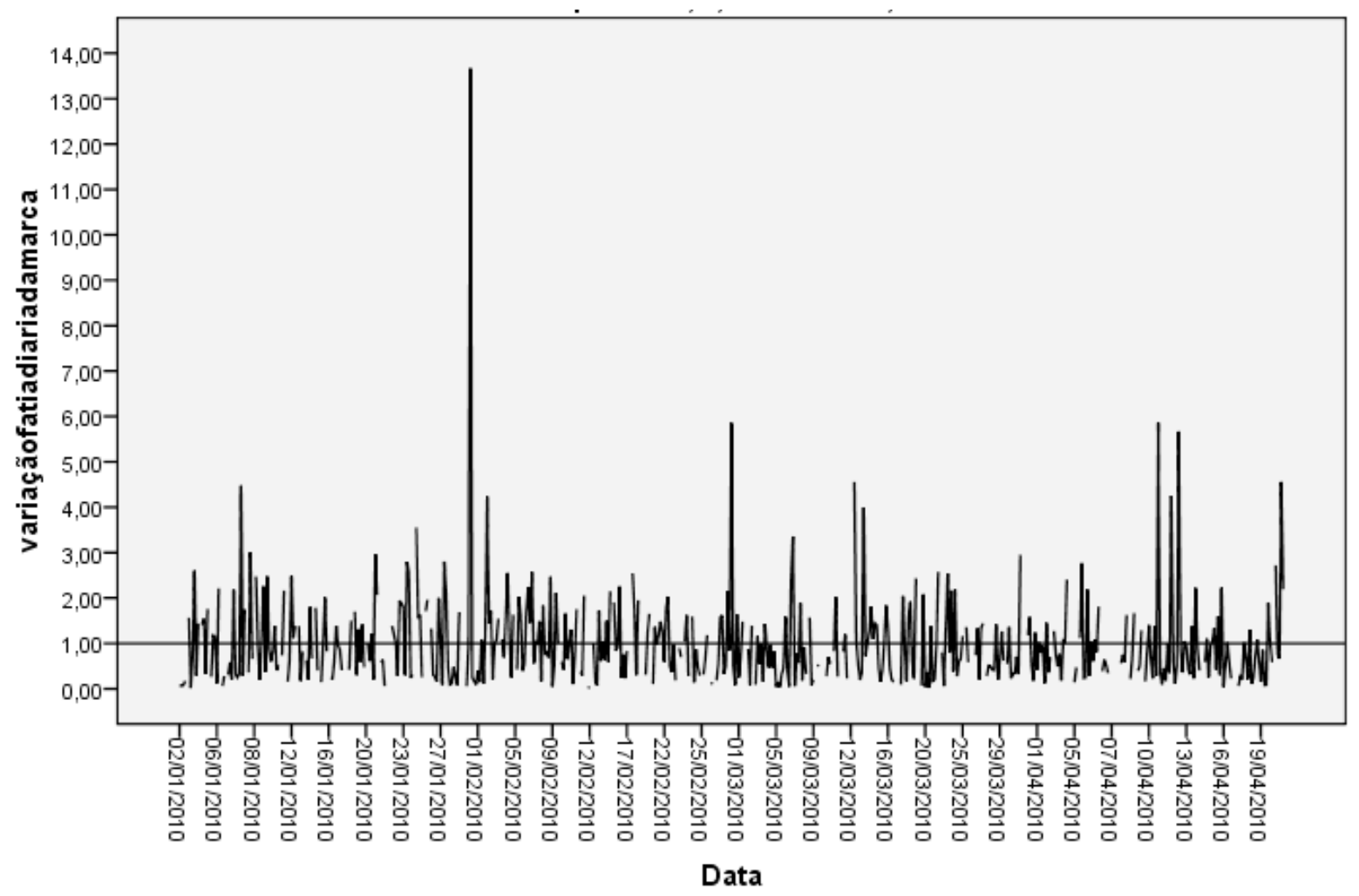

Figura 8 - Variação da Fatia Diária da Marca dos Produtos Essenciais de Baixo Nível Informativo

O próximo gráfico demonstrará a variação da fatia diária da marca dos produtos essenciais de nível informativo alto. 


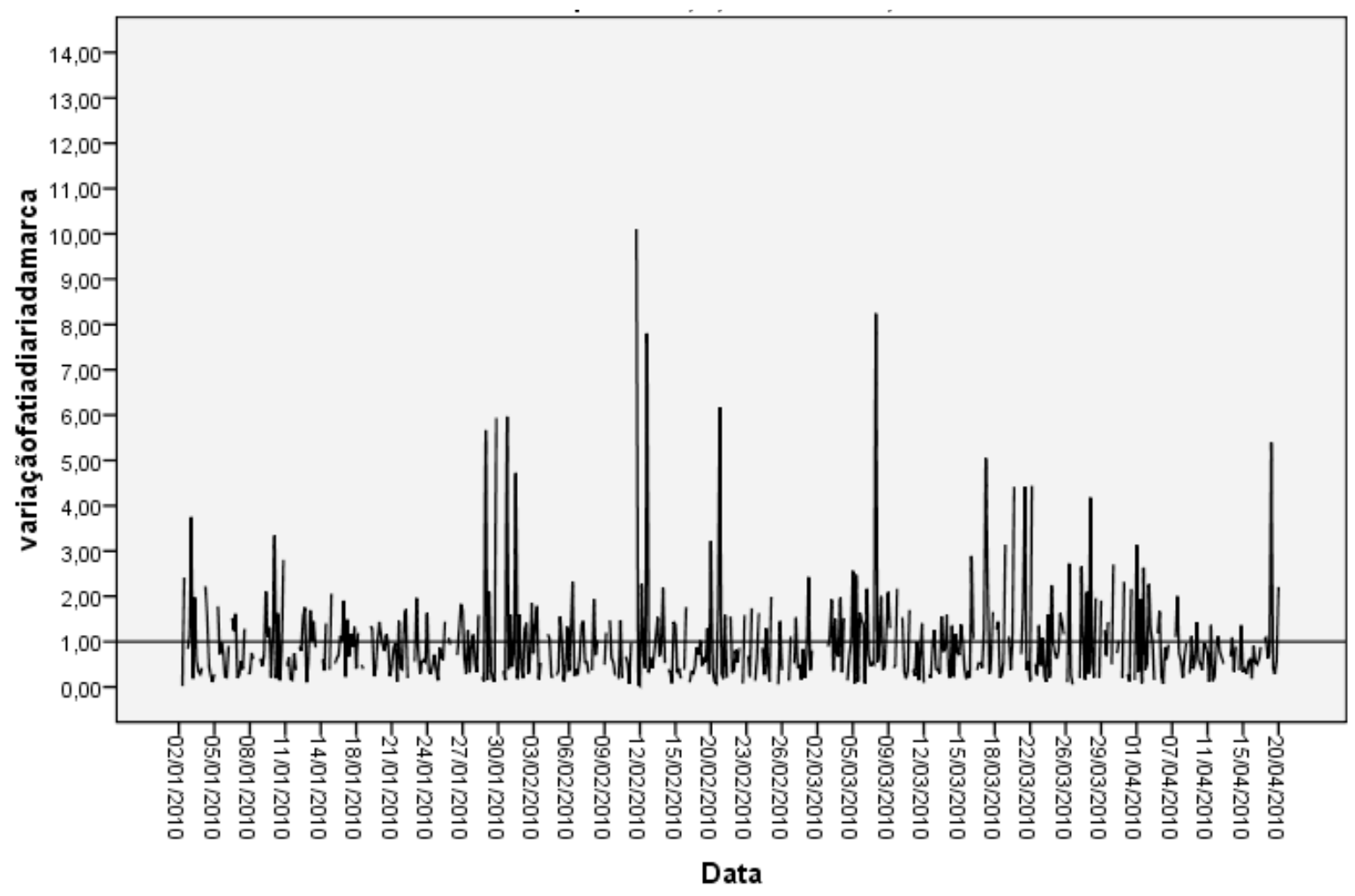

Figura 9 - Variação da Fatia Diária da Marca dos Produtos Essenciais de Alto Nível Informativo

Com a análise da Figura 9 é possível dizer que a discrepância relacionada ao dia 12/02/2010 é referente a um produto essencial de nível informativo alto. Sendo assim, os dois picos do gráfico representado pela figura 7 fazem parte dos produtos essenciais e prova o fato de que os produtos essenciais possuem maior variação da fatia de mercado diária quando comparados com os produtos supérfluos.

Analisados os produtos essenciais, chega o momento de analisar os produtos supérfluos. O gráfico a seguir ilustra a variação da fatia diária da marca de produtos supérfluos com nível informativo baixo. 


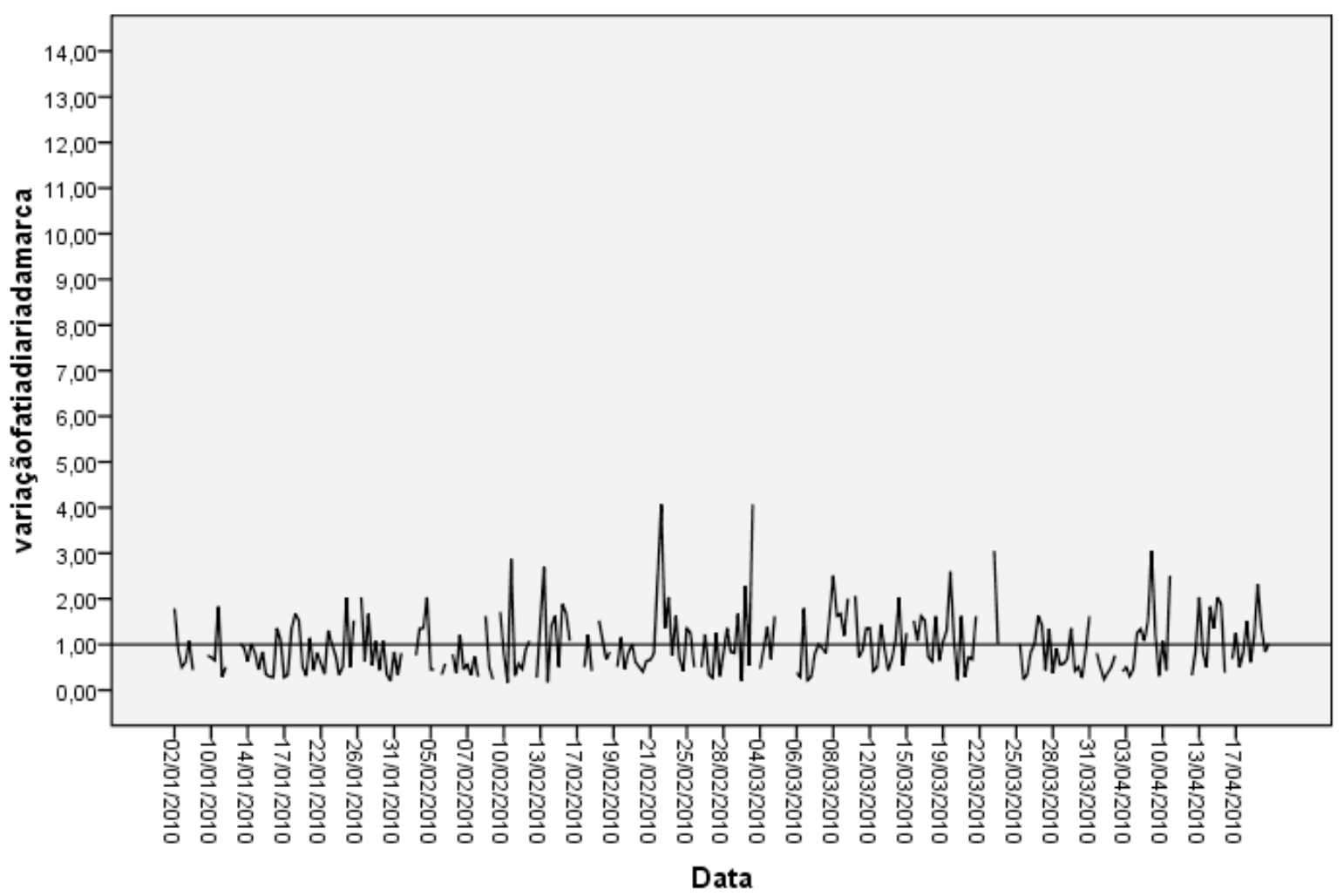

Figura 10 - Variação da Fatia de Mercado Diária da Marca dos Produtos Supérfluos de Baixo Nível Informativo

Os resultados comprovam que a variação da fatia de mercado diária da marca dos produtos supérfluos são menores quando comparadas com os produtos essenciais, ou seja os produtos essenciais são mais consumidos do que os produtos supérfluos.

Esse dado vai ao encontro do resultado da pesquisa realizada por Leugi (2008) e que foi apresentada na revisão teórica desse projeto. Segundo Leugi, de $91 \%$ a $100 \%$ dos participantes da pesquisa consomem rotineiramente os produtos classificados como essenciais que no caso são o arroz e o feijão. Já os supérfluos possuem percentagem de consumo rotineiro menor, o iogurte foi mencionado por $81 \%$ a $90 \%$ dos participantes enquanto o sorvete nem chegou a ser citado. Sendo assim, pode-se concluir que os produtos essenciais possuem consumo rotineiro maior do que os produtos classificados como supérfluos.

Para finalizar o ciclo de análise dos gráficos temporais dos tipos de produtos com controle dos benefícios informativos de suas marcas, resta analisar o gráfico de variação da fatia de mercado diária da marca dos produtos supérfluos com nível informativo alto. 


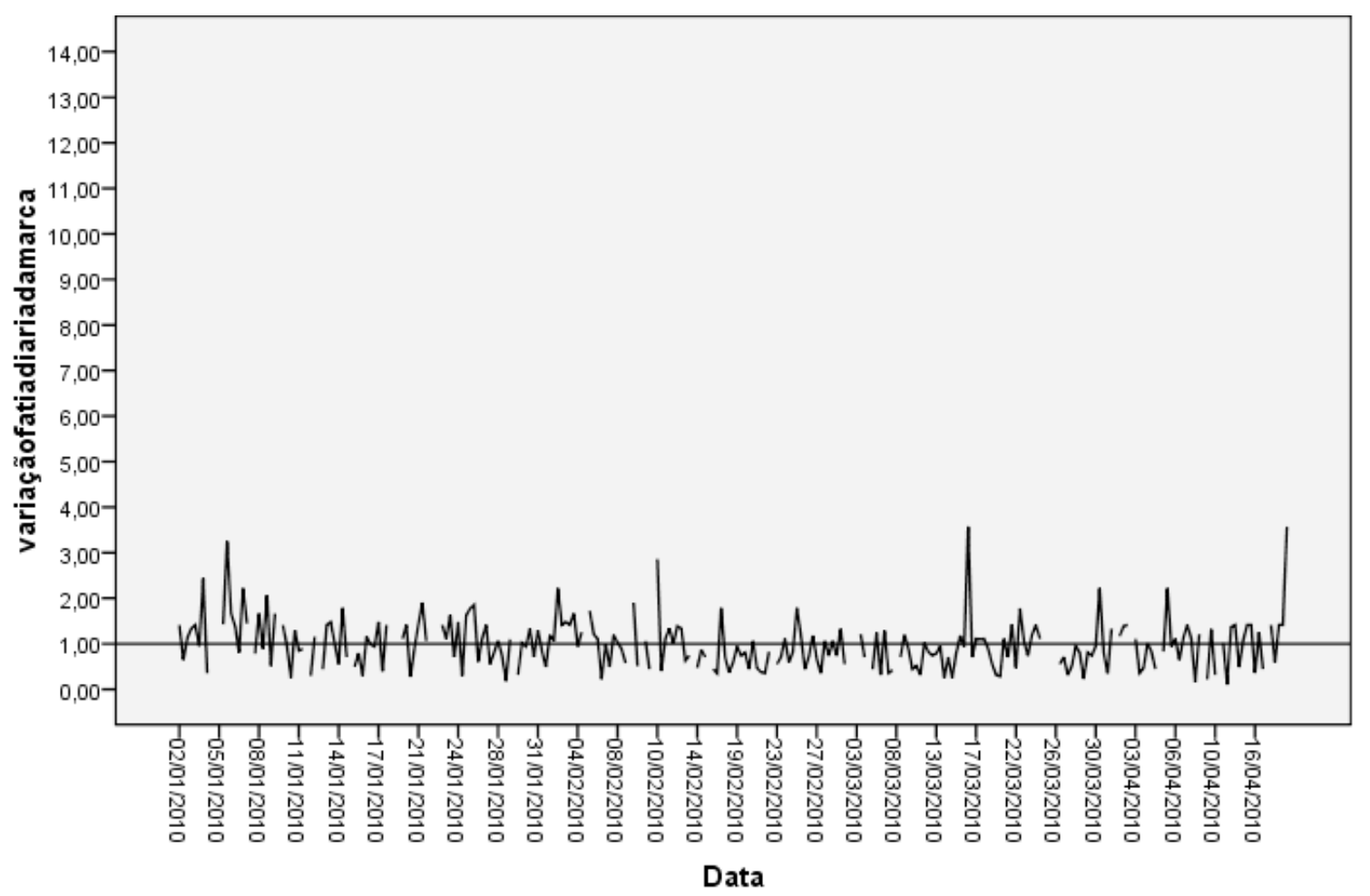

Figura 11 - Variação da Fatia de Mercado Diária da Marca dos Produtos Supérfluos de Alto Nível Informativo

A figura 9 assim como a figura 10, comprova que a variação da fatia diária da marca dos produtos supérfluos são menores do que a variação da fatia diária da marca dos produtos essenciais. Sendo que quando comparados entre si, os produtos supérfluos de marcas de benefício informativo baixo possuem maior variação da fatia diária da marca do que os produtos supérfluos com marcas de benefício informativo alto.

Como análise geral dos gráficos temporais observa-se que tanto os produtos essenciais quanto os produtos supérfluos demonstraram maior variação da fatia diária de mercado para as marcas de benefício informativo baixo. Esse resultado pode ser explicado por uma pesquisa realizada por Porto (2009) que concluiu que as marcas de nível informativo alto são mais potentes porque requerem menores variações das estratégias para que alcancem as mesmas fatias de mercado das de nível informativo baixo, portanto são mais constantes.

Após a análise da regressão ordinal da fatia de mercado diária, é o momento de analisar os resultados da regressão ordinal PLUM (Ploytomous Universal Model), na ferramenta SPSS selecionando o link function logit. Todas as 25 marcas dos quatro produtos disponibilizadas na loja foram inseridas na equação. 
Sendo assim, o próximo passo será apresentar a relação entre a variação da variável dependente de fatia diária de mercado ordinal em relação as variáveis independentes preço promocional, preço Premium, preço concorrencial, apresentação de propaganda geral e apresentação de propaganda folheto. $O R^{2}$ de Negelkerke para a análise das estratégias de preço é de apenas 0,213 ou seja, $21,3 \%$ da fatia de mercado diária relativa pode ser explicada pelas estratégias de preço citadas acima.

Tabela 5 - Parâmetro Estimado dos Produtos

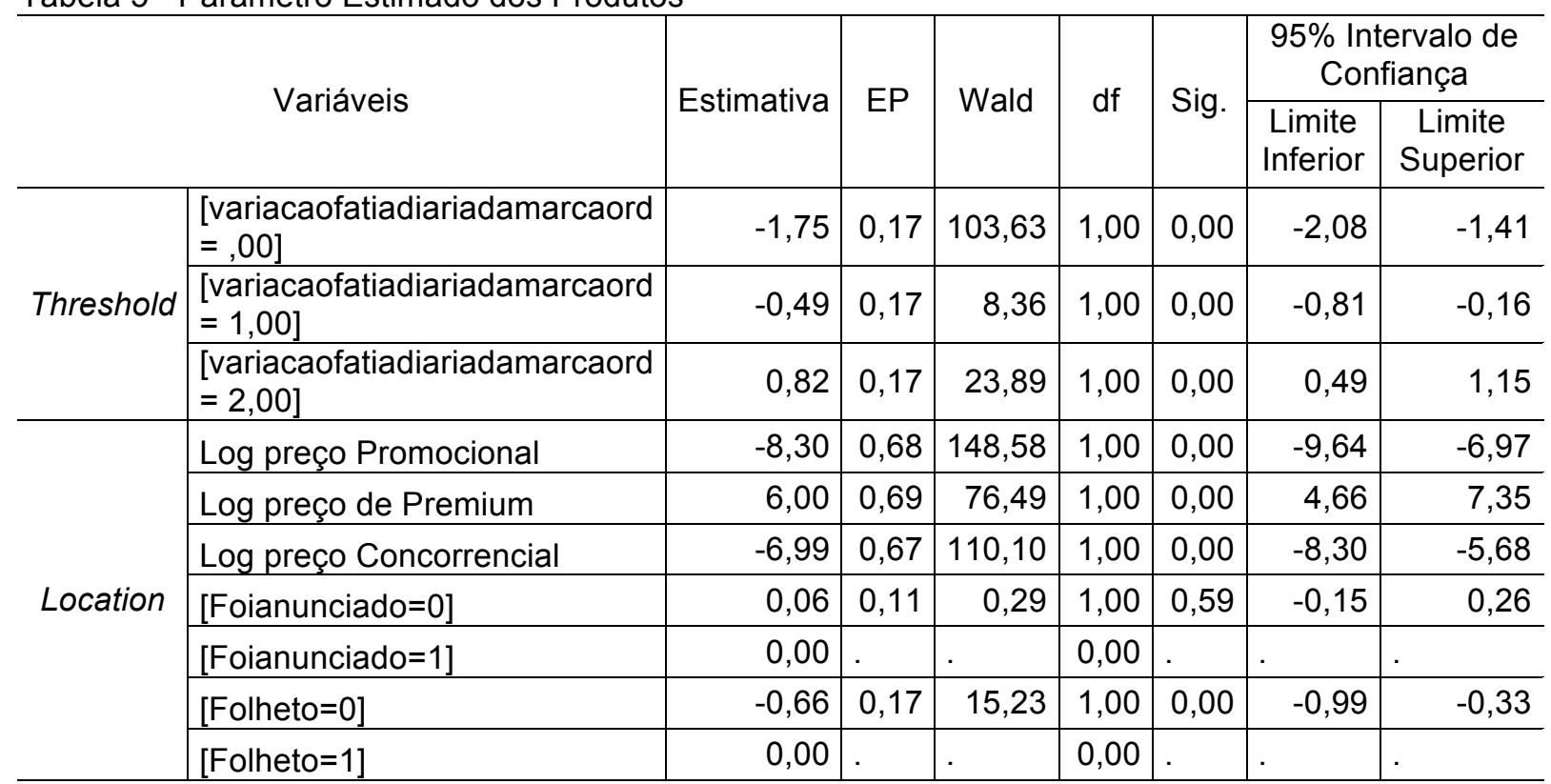

a: o parâmetro é 0 porque é redundante

b: Link Function: Logit

De acordo com a tabela número 5 os três tipos de preços são significativos em relação a variável dependente variação da fatia de mercado diária da marca, porém o que mais se destaca é o preço Premium que obteve uma relação positiva com estimativa igual a 6,00 e $p<0,01$. Esse resultado significa que quanto maior for o preço Premium maior será a fatia de mercado, o que pode fazer sentido para os casos de algumas marcas que já possuem clientes leais. Segundo Dominguez (2000), na maioria dos setores, os clientes mais leais estão dispostos a pagar (e pagam efetivamente) um preço premium em média $20 \%$ superior pela marca de sua preferência. Os demais resultados seguiram o padrão de quanto maior for o preço menor será a variação da fatia de mercado diária.

Em relação aos anúncios de propagandas gerais não existiu significância, esse fato pode ser explicado porque tirando o folheto que possui uma propaganda 
significativa para a marca os demais anúncios em televisão e rádio, por exemplo, influencia mais o marketing da loja e não da marca.

A segunda tabela a ser analisada ilustra os produtos essenciais de níveis informativos baixo sendo que a variável dependente é a fatia de mercado diária relativa e as variáveis independentes são o preço promocional, preço Premium, preço concorrencial apresentação de propaganda geral e apresentação de propaganda folheto seguindo a ordem utilizada na análise anterior.

Tabela 6 - Parâmetro Estimado dos Produtos Essenciais de Nível Informativo Baixo

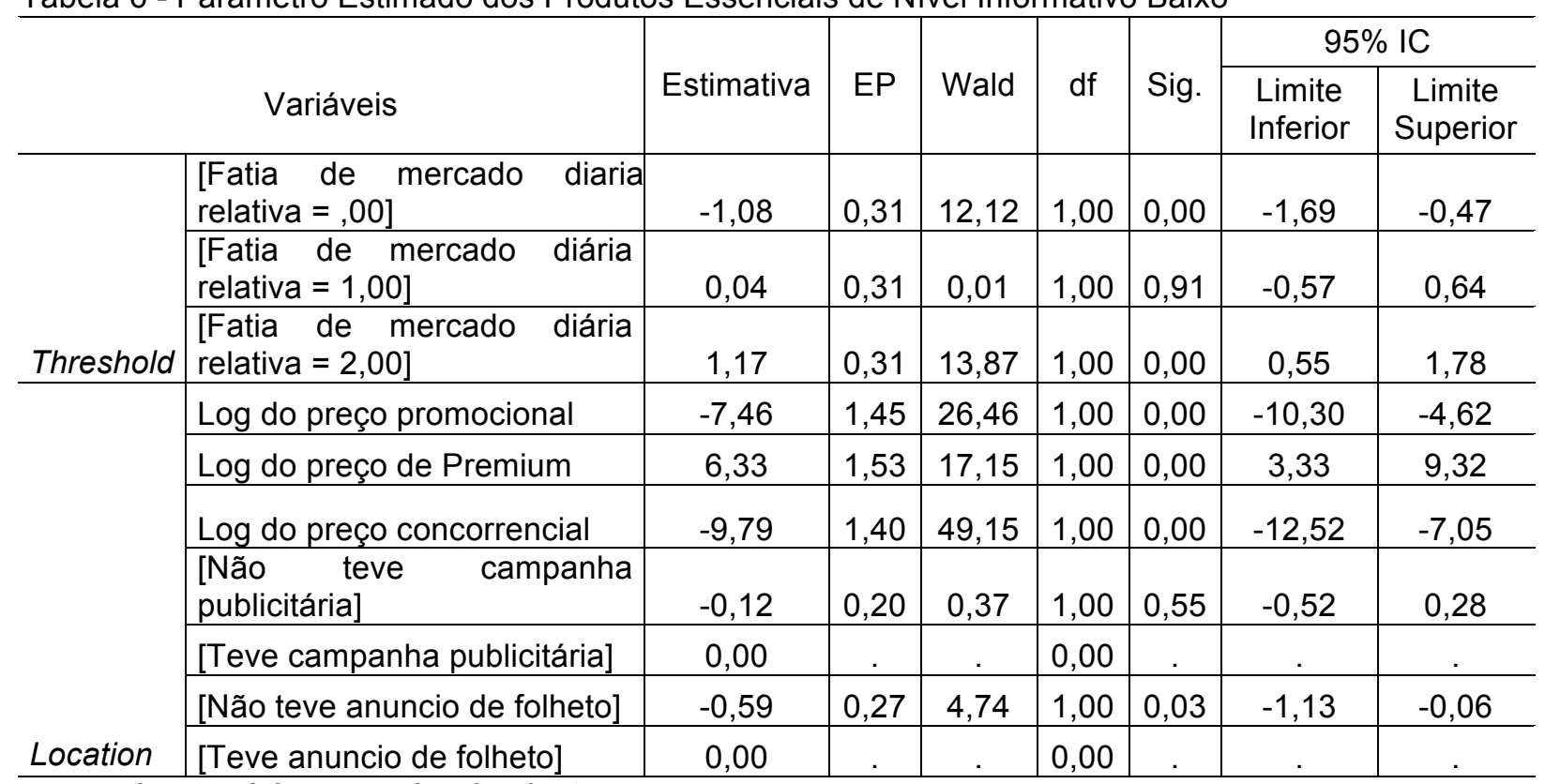

a: o parâmetro é 0 porque é redundante

b: Link Function: Logit

A Tabela 6 apresenta os resultados da análise de predição das variáveis de estratégias de preço do setor varejista que no caso foram: preço promocional, preço premium, preço concorrencial, ausência de campanha publicitária, campanha publicitária e ausência de anúncio de folheto e anúncio de folheto.

De acordo com a significância dessas variáveis os três tipos de preço, a ausência de anúncio no folheto e os anúncios de folheto possuem relação com a variável dependente fatia de mercado diária relativa. Sendo que a variável independente que obteve o maior impacto positivo assim como na tabela 5 foi 0 preço Premium (Estimativa $=6,326 ; p<0,01$ ), ou seja, para os casos dos produtos essenciais de nível informativo baixo quanto maior for o Preço Premium maior será a fatia de mercado diária, isso pode ocorrer, devido a uma mudança de posicionamento da marca e conseqüentemente aumento do preço poderá aumentar as suas vendas. 
Todas as demais variáveis possuem impacto negativo afinal a variável em questão é o preço e quanto maior for esse preço, menor será a fatia de mercado diária. Dentre elas a que se destaca é o preço concorrencial (Estimativa = -9,787; $p<0,01$.

Para completar a análise dos produtos essenciais segue agora a tabela 7 com os resultados dos produtos essenciais com alto nível informativo.

Tabela 7 - Parâmetro Estimado dos Produtos Essenciais de Nível Informativo Alto

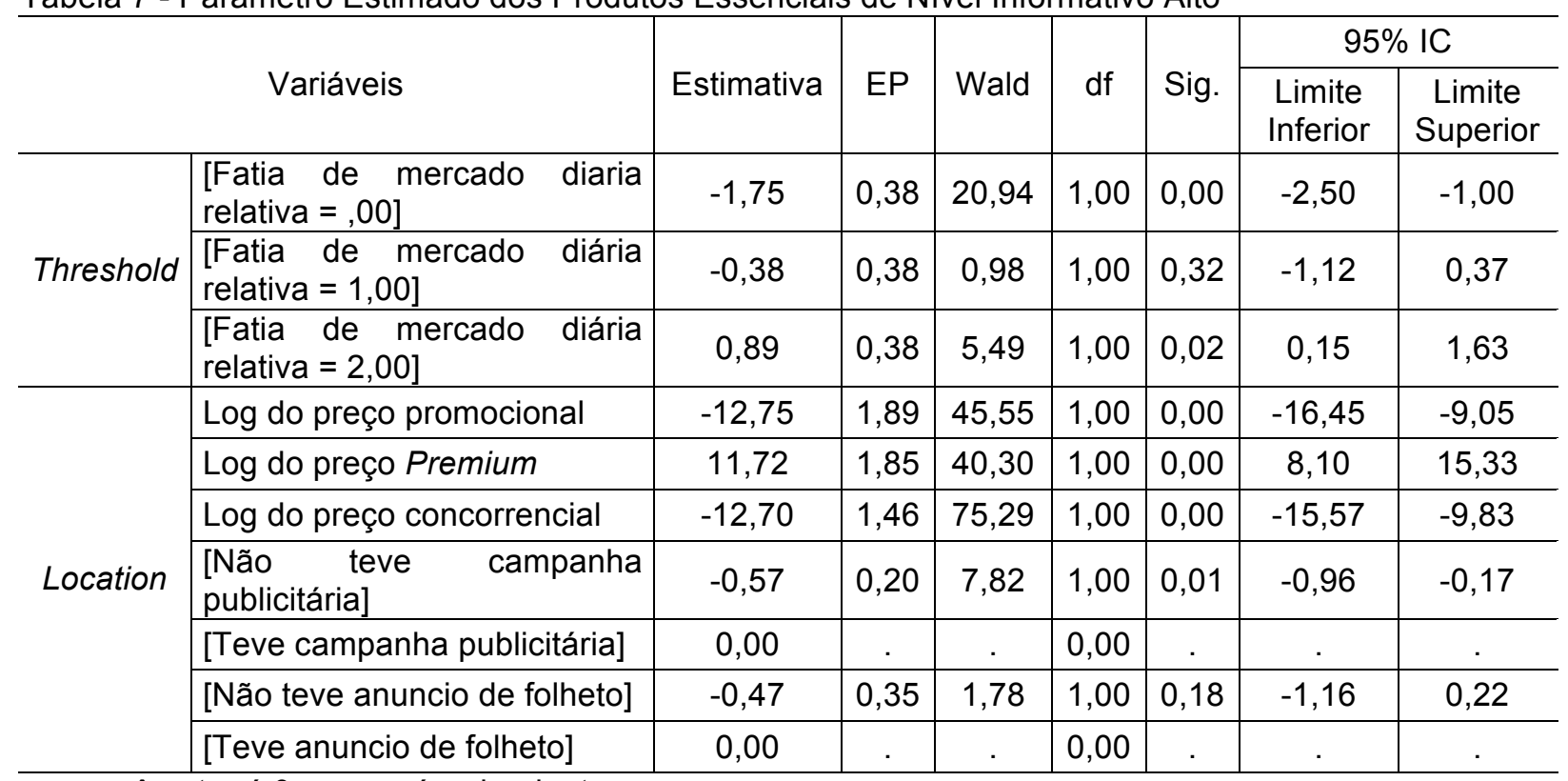

a: o parâmetro é 0 porque é redundante

b: Link Function: Logit

De acordo com a tabela 7, para os produtos essenciais de nível informativo alto as variáveis independentes que se relacionam com a fatia de mercado diária relativa são preço promocional, preço premium, preço concorrencial, ausência de campanha publicitária e campanha publicitária, pois todos obtiveram um $p$-valor menor que 0,05 . Nesse caso a estimativa do preço premium foi 11,72 quase o dobro da estimativa apresentada pelos produtos essenciais de nível informativo baixo 0 que demonstra que para os produtos essenciais de benefício informativo alto o aumento do preço premium impacta ainda mais na fatia de mercado diária relativa.

A ausência de campanha publicitária (Estimativa $=-0,57$ e $p<0,01$ ) nesse caso é preditora da fatia de mercado diária relativa, porém possui relação negativa o que significa para os produtos essenciais de benefício informativo alto estabelecer campanhas publicitárias regulares é importante para não deixar as vendas caírem.

Sendo assim, as características comuns entre os produtos essenciais são que as três estratégias de preço impactam de forma significativa a fatia de mercado diária relativa sendo que a única relação positiva foi a estratégia de preço premium. 
Para finalizar esse tópico de resultados e discussão resta apresentar como os produtos supérfluos se comportaram diante dos cenários pesquisados levando em consideração as três estratégias de preço, a apresentação de campanhas publicitárias gerais e a apresentação de campanhas publicitárias em folhetos. Segue a tabela 8 que apresenta o impacto nos produtos supérfluos de benefício informativo baixo.

Tabela 8 - Parâmetro Estimado dos Produtos Supérfluos de Nível Informativo Baixo

\begin{tabular}{|c|c|c|c|c|c|c|c|c|}
\hline & \multirow{2}{*}{ Variáveis } & \multirow{2}{*}{ Estimativa } & \multirow{2}{*}{$\mathrm{EP}$} & \multirow{2}{*}{ Wald } & \multirow{2}{*}{ df } & \multirow{2}{*}{ Sig. } & \multicolumn{2}{|c|}{$95 \%$ IC } \\
\hline & & & & & & & $\begin{array}{l}\text { Limite } \\
\text { Inferior }\end{array}$ & $\begin{array}{l}\text { Limite } \\
\text { Superior }\end{array}$ \\
\hline \multirow{3}{*}{ Threshold } & $\begin{array}{l}\text { [Fatia de mercado diaria } \\
\text { relativa }=, 00]\end{array}$ & $-2,69$ & 0,66 & 16,33 & 1,00 & 0,00 & $-3,99$ & $-1,38$ \\
\hline & $\begin{array}{l}\text { [Fatia de mercado diária } \\
\text { relativa }=1,00]\end{array}$ & $-1,13$ & 0,65 & 3,03 & 1,00 & 0,08 & $-2,41$ & 0,14 \\
\hline & $\begin{array}{l}\text { [Fatia de mercado diária } \\
\text { relativa }=2,00]\end{array}$ & 0,28 & 0,65 & 0,19 & 1,00 & 0,66 & $-0,99$ & 1,55 \\
\hline \multirow{7}{*}{ Location } & Log do preço promocional & $-5,46$ & 2,32 & 5,52 & 1,00 & 0,02 & $-10,01$ & $-0,90$ \\
\hline & Log do preço de Premium & 0,98 & 1,65 & 0,35 & 1,00 & 0,55 & $-2,26$ & 4,22 \\
\hline & Log do preço concorrencial & $-0,02$ & 1,32 & 0,00 & 1,00 & 0,99 & $-2,60$ & 2,56 \\
\hline & $\begin{array}{l}\text { [Não teve campanha } \\
\text { publicitária] }\end{array}$ & 0,53 & 0,33 & 2,58 & 1,00 & 0,11 & $-0,12$ & 1,18 \\
\hline & [Teve campanha publicitária] & 0,00 & . & . & 0,00 & . & . & . \\
\hline & [Não teve anuncio de folheto] & $-1,25$ & 0,58 & 4,66 & 1,00 & 0,03 & $-2,38$ & $-0,11$ \\
\hline & [Teve anuncio de folheto] & 0,00 & & & 0,00 & . & & . \\
\hline
\end{tabular}

a: o parâmetro é 0 porque é redundante

b: Link Function: Logit

De acordo com a tabela 8, o preço promocional, a ausência de anúncio em folheto e o anúncio em folheto foram considerados preditoras da variável fatia de mercado diária relativa. Sendo que o preço promocional possui relação negativa com estimativa igual a $-5,46$, ou seja, quanto menor for o preço maior será a fatia de mercado diária relativa. Isso pode ser explicado pelo fato de ser um produto supérfluo e uma vez que o consumidor julgar que o preço está acima do que considera justo pagar por ele poderá tomar a decisão de não comprar facilmente. Porém, ao contrário o mesmo acontece, se o consumido julgar que o preço está abaixo do que considera justo pagar por ele poderá tomar a decisão de comprar facilmente. Thaler (1985) argumenta que o preço percebido como justo, depende em grande escala da percepção que o consumidor tem sobre o custo do produto para o vendedor. Mas além dessa percepção existem também outras percepções como a 
da marca que está sendo analisada nesse trabalho através da classificação em níveis informativo.

A ausência de anúncio em folhetos também demonstra relação negativa com estimativa igual a $-1,25$. Sendo assim, quanto mais anúncios em folhetos forem feitos maior será a fatia de mercado diária relativa dos produtos supérfluos de benefício informativo baixo. Meloche (1988) complementa afirmando que em sua pesquisa encontrou que, que isoladamente os anúncios não influenciam as vendas das marcas é preciso interagir com o preço e tipo de produto. O que confirma o que está apresentado na tabela 9 que informa que o preço promocional e o anúncio de folhetos são significantes e aumentam a fatia de mercado diária relativa.

Por fim, segue a análise dos produtos supérfluos de marcas de benefício informativo alto em relação ao impacto das estratégias de preço e propaganda na fatia de mercado diária relativa. Após a análise da tabela 10 pode ser possível encontrar um padrão de comportamento para os produtos supérfluos.

Tabela 9 - Parâmetro Estimado dos Produtos Supérfluos de Nível Informativo Alto

\begin{tabular}{|c|c|c|c|c|c|c|c|c|}
\hline & \multirow{2}{*}{ Variáveis } & \multirow{2}{*}{ Estimativa } & \multirow{2}{*}{ EP } & \multirow{2}{*}{ Wald } & \multirow{2}{*}{ Df } & \multirow{2}{*}{ Sig. } & \multicolumn{2}{|c|}{$95 \%$ IC } \\
\hline & & & & & & & $\begin{array}{l}\text { Limite } \\
\text { Inferior }\end{array}$ & $\begin{array}{l}\text { Limite } \\
\text { Superior }\end{array}$ \\
\hline \multirow{3}{*}{ Threshold } & $\begin{array}{l}\text { [Fatia de mercado diaria } \\
\text { relativa }=, 00]\end{array}$ & $-2,80$ & 0,46 & 36,83 & 1,00 & 0,00 & $-3,71$ & $-1,90$ \\
\hline & $\begin{array}{l}\text { [Fatia de mercado diária } \\
\text { relativa }=1,00]\end{array}$ & $-1,08$ & 0,43 & 6,36 & 1,00 & 0,01 & $-1,92$ & $-0,24$ \\
\hline & $\begin{array}{l}\text { [Fatia de mercado diária } \\
\text { relativa }=2,00]\end{array}$ & 0,88 & 0,42 & 4,27 & 1,00 & 0,04 & 0,05 & 1,71 \\
\hline \multirow{7}{*}{ Location } & Log do preço promocional & $-3,29$ & 2,38 & 1,91 & 1,00 & 0,17 & $-7,94$ & 1,37 \\
\hline & Log do preço premium & 0,53 & 1,95 & 0,07 & 1,00 & 0,79 & $-3,30$ & 4,36 \\
\hline & Log do preço concorrencial & $-6,45$ & 1,64 & 15,37 & 1,00 & 0,00 & $-9,67$ & $-3,22$ \\
\hline & $\begin{array}{l}\text { [Não teve campanha } \\
\text { publicitária] }\end{array}$ & 0,15 & 0,34 & 0,20 & 1,00 & 0,65 & $-0,52$ & 0,83 \\
\hline & [Teve campanha publicitária] & 0,00 & . & . & 0,00 & . & . & . \\
\hline & [Não teve anuncio de folheto] & $-0,12$ & 0,39 & 0,09 & 1,00 & 0,77 & $-0,87$ & 0,64 \\
\hline & [Teve anuncio de folheto] & 0,00 & . & . & 0,00 & . & . & . \\
\hline
\end{tabular}

a: o parâmetro é 0 porque é redundante

b: Link Function: Logit

De acordo com a tabela 9 apenas o preço concorrencial (estimativa $=6,45 ; p$ $<0,01)$ é considerado preditor da variável dependente fatia de mercado diária relativa nos casos dos produtos supérfluos de benefício informativo alto. Sendo assim, uma marca conhecida e percebida como de alta qualidade quando diminui o seu preço aumenta a sua fatia de mercado diária relativa. Pode-se dizer que esse 
fato ocorre principalmente quando os produtos não possuem diferenciações relevantes em relação ao concorrente, pois como a marca já é conhecida e possui qualidade o consumidor toma a decisão com base no preço concorrencial.

Outra conclusão interessante que pode ser visualizada na tabela 10 é o fato de que ter campanhas publicitárias em geral ou não, e ter anúncios em folhetos ou não, estão fora da análise por não serem significantes o que prova que no caso dos produtos supérfluos de benefício informativo alto o consumidor já tem uma preferência por um determinado produto e compra independente de estar com o preço promocional ou com um preço Premium. Esse resultado vai de encontro com a pesquisa realizada por Pohl (2008) que diz que para os produtos Margarina e Café o tempo de procura para as marcas de benefício informativo alto é menor quando comparado com o tempo de procura de marcas de benefício informativo baixo. Ou seja, as pessoas já sabem o que querem consumir por já conhecer a marca.

Resumindo as tabelas de parâmetros estimados pode-se dizer que para cada tipo e benefício informativo do produto existe uma ou mais estratégia de definição de preço e propaganda específica para atender o objetivo de aumentar a fatia de mercado da marca relativa.

Porto (2009) afirma que quanto maior foi o nível informativo das marcas, maior será a fatia e penetração de mercado corroborando com o resultado da pesquisa que chegou a conclusão de que para os produtos essenciais as estratégias das marcas de nível informativo alto são mais efetivas do que as de nível informativo baixo, com destaque para a estratégia de anúncio em folhetos que parece estimular apenas as marcas de benefício informativo baixo. Por outro lado, quando o produto for supérfluo, diferentes estratégias de marketing estimulam a fatia de mercado diária a depender do nível informativo. 


\section{CONCLUSÕES E RECOMENDAÇÕES}

O objetivo geral do trabalho foi avaliar o impacto das estratégias de marketing na fatia de mercado, com o controle dos benefícios informativos das marcas em produtos essenciais e supérfluos. Para alcançar esse objetivo foram realizados estudos com base em dados primários e secundários que analisaram a fatia de mercado de duas formas: agregada e diária.

A primeira foi a análise agregada que visava avaliar a influencia das estratégias de propaganda e preço na fatia agregada de mercado e identificou que a quantidade de propaganda relativa média do produto possui grau de relevância de $83 \%$ com a variável dependente fatia de mercado agregada de venda relativa ao produto. Isso quer dizer que $83 \%$ da fatia de mercado agregada se relaciona com a quantidade de propaganda.

De acordo com a análise agregada de todas as 25 marcas que englobam produtos essenciais e supérfluos de benefício informativo alto e baixo, pode-se dizer que a maior parte das marcas realiza pouca propaganda e conseqüentemente possui pequena participação de mercado com exceção de algumas marcas que provavelmente são as líderes de mercado de cada produto que estão 1,5 acima da média de quantidade de propaganda relativa média do produto $\mathrm{e}$ conseqüentemente, estão também 1,5 acima da média da fatia de mercado total de venda relativa ao produto.

Por outro lado surpreendentemente, observa-se que essa relação agregada não é significativa quando se trata da análise do preço médio em relação a fatia de mercado. A variável independente "preço médio" sequer se mostrou significativa para a variável dependente "fatia de mercado agregada".

O segundo estudo utilizou a fatia de mercado diária e visava analisar a influência das estratégias de propaganda e preço da fatia diária de mercado. Os primeiros resultados comprovaram que a variação da fatia de mercado diária da marca dos produtos supérfluos é menor quando comparada com os produtos essenciais, ou seja, como já era de se esperar os produtos essenciais são mais consumidos do que os produtos supérfluos.Nesse caso, a estratégia de preço que mais se destacou com foi o preço promocional. 
O terceiro estudo também utilizou a fatia de mercado diária como variável dependente, porém visava analisar a influência das estratégias de propaganda e preço da fatia diária de mercado com o controle dos benefícios informativos em produtos essenciais e supérfluos e concluiu que tanto os produtos essenciais quanto os produtos supérfluos demonstraram maior variação da fatia diária de mercado para as marcas de benefício informativo baixo. O que quer dizer que os produtos de benefício informativo alto possuem um maior poder em relação aos de baixo nível informativo e por isso demonstram um comportamento mais constante.

Visando atender os objetivos específicos (1) analisar a relação preditiva entre a disponibilização de propaganda em geral, nos folhetos promocionais, preço promocional, preço premium e preço concorrencial na fatia de mercado diária das marcas e (2) analisar a relação preditiva entre a disponibilização de propaganda em geral, folhetos promocionais, preço promocional, preço premium e preço concorrencial na fatia de mercado diária, com controle dos benefícios informativos das marcas em produtos essenciais e supérfluos. O modelo encontrou aos seguintes resultados.

De uma forma geral, os três tipos de preços são significativos em relação a variável dependente variação da fatia de mercado diária da marca, porém o que mais se destaca é o preço concorrencial, pois significa que quanto maior for o preço da marca no dia comparado com o preço médio do produto nesse dia maior será a fatia de mercado. Um fato curioso foi em relação aos anúncios de propagandas gerais que não obteve significância com a variável fatia de mercado diária relativa, esse fato pode ser explicado porque tirando o folheto que possui propagandas significativas para a marca os demais anúncios em televisão e rádio, por exemplo, possuem maior influência com a imagem da empresa e não da marca.

Para os produtos essenciais de nível informativo baixo a estratégia de preço que mais se destacou assim como na análise dos produtos gerais foi o preço concorrencial,ou seja, quanto menor for o preço concorrencial maior será a fatia de mercado diária. Para os produtos essenciais de nível informativo alto podem ser utilizados o preço promocional, o preço premium, o preço concorrencial, a ausência de campanha publicitária e a campanha publicitária como estratégias que se relacionam com a fatia de mercado diária relativa, o que quer dizer que nesse caso anúncios publicitários que não sejam folhetos impactam a fatia de mercado. 
Para os produtos supérfluos de nível informativo baixo a estratégia que mais se destacou foi o preço promocional que possui relação negativa com estimativa igual a $-5,46$, ou seja, quanto menor for o preço maior será a fatia de mercado diária relativa. Isso pode ser explicado pelo fato de ser um produto supérfluo e uma vez que o consumidor julgar que o preço está acima do que considera justo pagar poderá tomar a decisão de não comprar. Porém, o contrário também acontece, se o consumido julgar que o preço está abaixo do que considera justo pagar poderá tomar a decisão de comprar facilmente.

Para os produtos supérfluos de nível informativo alto apenas a estratégia de preço concorrencial deverá ser utilizada. Sendo assim, uma marca conhecida e percebida como de alta qualidade quando diminui o seu preço aumenta a sua fatia de mercado diária relativa.

De acordo com os resultados acima é possível responder o problema levantado no início dessa pesquisa. Será que as estratégias de marketing influenciam as fatias de mercado de forma diferenciada para marcas que oferecem benefícios informativos distintos tanto para produtos essenciais quanto supérfluos?

A resposta é sim. Para cada tipo de produto e benefício informativo existe uma ou mais estratégia de definição de preço e propaganda que pode influenciar mais ou menos e ser positiva ou negativa em relação a fatia de mercado. Agora os gerentes de marketing poderão tomar decisões de forma mais embasada e mensurar os resultados gerados por essas decisões.

As limitações enfrentadas para esse trabalho foram os fatos de só ter acesso às informações de propagandas em geral e de folhetos o que impossibilitou a mensuração da relevância dos demais tipos de anúncios como rádio, televisão e carro de som, e ter acesso apenas a quatro produtos, pois quanto maior for a quantidade de dados utilizados melhor será a análise.

As críticas a esse trabalho são que não foi possível avaliar o benefício utilitário das marcas e a lucratividade média desses produtos, o que pode ser uma idéia para o próximo estudo já que as variáveis necessárias para essa análise serão o preço, a quantidade vendida e o custo dos produtos, sendo que duas delas já estão compreendidas nessa pesquisa. 


\section{REFERÊNCIAS}

AUFREITER, N. A.; ELZINGA, D.; GORDON, J.W. "Better Branding". The Mckinsey Quartely, 2003, n. 4, p. 1.

ABIB J. A. D. Teoria moral de Skinner e desenvolvimento humano. Psicologia: reflexão e crítica. Porto Alegre, v. 14. n. 1, p. 101-117, 2001.

ALHADEFF, D. A. Microeconomics and human behavior: Toward a new synthesis of economics and psychology. Berkeley, CA: University of California Press, 1982.

AMARAL, S.A. Marketing da informação: entre a promoção e a comunicação integrada de marketing. Inf. \& Soc.:Est., João Pessoa, 2008.

BALEEIRO, A. Limitações constitucionais ao poder de tributar. 7. ed. Rio de Janeiro: Forense, 1997.

BIGAL, S. O que é criação publicitária ou o estético na publicidade. 2 ed. São Paulo: Nobel, 1999.

BOTELHO, D; URDAN, T. Lealdade à marca e sensibilidade ao preço: um escolhe da marca pelo consumidor. Revista da Administração Contemporânea. v. 9, n. 4, Out./Dez. 2005.

BUARQUE, A. O Minidicionário da Língua Portuguesa, século XXI. 4 ed. Rio de Janeiro: Nova Fronteira, 2001.

CATANIA, A.C. Aprendizagem: comportamento, linguagem e cognição. Porto Alegre: Artmed, 1999.

COBRA, Marcos. Administração de marketing no brasil. 2ed. São Paulo: Cobra Editora . 2005.

COMPANHIA DE PLANEJAMENTO DO DISTRITO FEDERAL. Sítio eletrônico. Disponível em: <http://www.codeplan.df.gov.br/>. Acesso em: 20 jun. 2010.

COSTA, C; SANTOS, A. Características Gerais do Varejo no Brasil. BNDES Setorial, 1997. 
CRESWELL, J. W. Projeto de pesquisa: métodos qualitativo, quantitativo e misto. 2.ed. Porto Alegre: Artmed, 2007.

CZINKOTA, Michael R.; et al. Marketing: as melhores práticas. Porto Alegre: Bookman, 2001.

DE-FARIAS, A. K. C. R. Comportamento Social: Cooperação, Competição e Trabalho Individual. In: Análise do Comportamento: pesquisa, teoria e aplicação. ABREU- RODRIGUES, J.; RIBEIRO, M. R. (orgs.), Porto Alegre, RS: Artmed, 2005.

FILHO, L; LEPSCH, S. Comunicação de marketing em redes de pequenos supermercados: um estudo de caso na associação regional de supermercados do interior do estado de São Paulo. REA: revista eletrônica de administração, São Paulo: FACEF, v. 3, n. 1, 2004.

FLORES, C; DAMACENA, C. Análise dos Efeitos da Percepção de Valor de um Programa de Fidelidade na Lealdade à Marca. Rio de Janeiro: XXXII Encontro ANPAD. 2008.

FOXALL, G. R. Consumer psychology in behavioral perspective. New York: Routledge, 1990.

1997

Marketing psychology: the paradigm in the wings. London: MacMillan,

Radical behaviorist interpretation: generating and evaluating an account of consumer behavior. The Behavior Analyst, 1998.

FOXALL, G. R.; OLIVEIRA, C, J. M; SCHREZENMAIER, T. C. The behavioral economics of consumer brand choice: patterns of reinforcement and utility maximization. Behavioural Processes, 2004.

FREITAS, L. Como aumentar a eficiência da publicidade? (2007) - disponível em: http://www.mktg2.net/2007/10/23/

GRACIOSO, F.; PENTEADO, J. Cinqüenta anos de vida e propaganda brasileiras. São Paulo: Mauro Ivan Marketing Editorial, 2001.

GÜNTHER, H. Pesquisa qualitativa versus pesquisa quantitativa: esta é a questão? Psicologia: Teoria e Pesquisa, Brasília, v. 22. n. 2, p. 201 - 209, maio/ago. 2006. 
INSTITUTO BRASILEIRO DE GEOGRAFIA ESTATÍSTIVAS. Sítio eletrônico. Disponível em <http://www.ibge.gov.br/home/presidencia/noticias/noticia_visualiza.php?id_noticia=1 638\&id_pagina=1>. Acesso em: 20 jun. 2010.

KELLER, K.L. Strategic brand management: building, measuring, and managing brand equity. Upper Saddle River, New Jersey: Prentice Hall, 1998.

KERLINGER, F. N. Metodologia da pesquisa em ciências sociais: um tratamento conceitual. São Paulo : EPU/EDUSP, 1980.

KOTLER, P.; KELLER, K. L. Administração de marketing. 12 ed. São Paulo: Pearson Prentice Hall, 2006.

KOTLER, P; ARMSTRONG, G. Princípios de marketing. 12. ed. São Paulo: Pearson Prentice Hall, 2007.

LEUGI, G. Práticas de consumo e economia de escala: caracterização de comportamentos e contingências. São Carlos: Anal Cortegoso, 2008.

MALHOTRA. N. Marketing research: an apllied orientation. 4 ed. Porto Alegre: Artmed, 2004.

MALUF, R. Consumo de alimentos no brasil: traços gerais e ações públicas locais de segurança alimentar. São Paulo. 2000.

MANKYW Gregory. Introdução a economia. 5 ed. São Paulo: CENGAGE Learning. 2009.

MCCARTHY, J. E; PERREAULT, W. D. Marketing essencial: uma abordagem gerencial e global. São Paulo: Atlas, 1997.

MORRIS, Michael H.; MORRIS, G. Política de preços em um mercado competitivo e inflacionado. São Paulo, Makron Books, 1994.

MUSATTI, R; PLENS, M; ARAÚJO, C; BERTO, P. Marcas ou Preços: a preferência do consumidor no mercado de produtos de consumo do autoserviço brasileiro. São Paulo. 2002.

NEVES, J. A.D; PESSOA R.W.A. Causas da mortalidade de micros e pequenas empresas: o caso das lojas de um shopping Center. Organizações em contexto, a. 2, 2006. 
NEVES, P; CARDOSO, A. Atitude dos consumidores relativamente à marca dos distribuidores. Revista da Faculdade de Ciências Humanas e Sociais. Porto. 2008.

NONAKA, I; TAKEUCHI, H. Criação de conhecimento na empresa. Rio de Janeiro:Campus. 1997.

OLIVEIRA C; J. M., FOXALL, G. R.; SCHREZENMAIER, T. C. Consumer brand choice: Individual and group analyses of demand elasticity. Journal of the Experimental Analysis of Behavior, v. 85, n. 2, p. 147-166, 2006.

OLIVEIRA, C; J. M. Effects of base price upon search behavior of consumers in a supermarket: An operant analysis. Journal of Economic Psychology, v. 24, n. 5, p. 637- 652, 2003.

PEREIRA, C; CABELLO, O; GALLO, M. Impactos do imposto sobre produtos industrializados nos custos da produção de cigarros no Brasil. Universidade de São Paulo, 2007.

PINHEIRO, R. M.; CASTRO, G. C; SILVA, H. H. Comportamento do consumidor e pesquisa de mercado. Rio de Janeiro: FGV Editora, 2006.

POHL, R. Efeitos do nível de reforço informativo das marcas sobre a duração do comportamento de procura. Dissertacao de Mestrado. Universidade de Brasilia, Brasilia, 2004.

POHL R.; OLIVEIRA C J. Efeitos do Nivel de Beneficio Informativo das Marcas sobre a Duracao do Comportamento de Procura. Revista da Administração Contemporânea Eletrônica, v. 2, n. 3, p. 449-469. 2008.

RABAÇA, C. A.; BARBOSA, G. Dicionário de comunicação. Rio de Janeiro: Codecri. 1978.

RICHARDSON, R. J. (Org.). Pesquisa social: métodos e técnicas. 3.ed. São Paulo: Atlas, 1999.

ROCHA, A; CHRISTENSEN, C. Marketing teoria e prática no brasil. São Paulo: Atlas, 1999.

RYLE,G.. The concept of mind. London: Hutchinson \& Co Sandall. H, 1949. 
SANT'ANNA, A. Propaganda - teoria, técnica, prática. 7 ed. São Paulo: Pioneira, 2000.

SHIMP, T. Propaganda e promoção: aspectos complementares da comunicação integrada de marketing. 5a edição. São Paulo. Bookman. 2002.

SIMON, H. Price management. 2nd ed. Amsterdam: Elsevier Science Publishers, 1989.

SKINNER, B. F. Verbal behavior. Englewood Cliffs, NJ: Prentice-Hall, 1957.

SMITH, D. C. PARK, W. The Effects of Brand Extensions on Market Share and Advertising Efficiency. Journal of Marketing Research, v. 29, n. 3. Aug. 1992, p. 296-313.

THALER, R. Mental Accounting Matters, Journal of Behavioral Decision Making, v.12, p.183-206, 1999.

URBAN, G, L.; CARTER, T.; GASKIN, S,; MUCHA, Z. Market share rewards to pioneering brands: na empirical analysis and strategic implications. Manegement Science, v. 32, n. 6, jun., 1986, p. 645-659.

VERGARA, S. C. Projetos e relatórios de pesquisa em Administração. 3.ed. São Paulo: Atlas, 2000. 


\title{
APÊNDICES
}

\section{Apêndice A - Questionário De Nível Informativo}

\author{
QUESTIONÁRIO
}

Caro Consumidor,

Gostaríamos de obter informações sobre algumas marcas de produtos que estão a venda em supermercados e lojas de conveniência. Esse questionário tem o objetivo de identificar quanto diferentes marcas são conhecidas pelos consumidores e como eles avaliam a qualidade dessas mesmas marcas.

Abaixo estão listadas marcas de quatro produtos: Arroz tipo $15 \mathrm{Kg}$, Feijão Carioca $1 \mathrm{Kg}$, Sorvete de Flocos e logurte de Chocolate. Para cada marca, você deve marcar o quanto você julga que ela seja conhecida e como você avalia o seu nível de qualidade. Por favor, use as chaves de respostas abaixo, escrevendo os números que melhor representam a sua avaliação de cada uma das marcas.

\section{A marca é conhecida?}

0 . Desconhecida

1. Pouco conhecida

2. Medianamente conhecida

3. Muito conhecida

\section{Qual é o nível de qualidade da marca?}

0 . Sem opinião

1. Baixa qualidade

2. Média qualidade

3. Alta qualidade

\begin{tabular}{|l|l|l|l|l|l|}
\hline \multicolumn{1}{|c|}{ ARROZ } & CONHECIDA? & QUALIDADE? & FEIJÃO CARIOCA & CONHECIDA? & QUALIDADE? \\
\hline Tio João & & & Da Casa & & \\
\hline Biju & & & Kicaldo & & \\
\hline Dona Xepa & & & Da Mamãe & & \\
\hline Camil & & & Perola & & \\
\hline Kicaldo & & Tio Jorge & & \\
\hline Extremo Sul & & & Dona Xepa & & \\
\hline Tio Jorge & & & Delícia & & \\
\hline Doura & & & & & \\
\hline Namorado & & & SORVETE DE & CONHECIDA? & QUALIDADE? \\
\hline $\begin{array}{l}\text { IOGURTE DE } \\
\text { CHOCOLATE }\end{array}$ & CONHECIDA? & QUALIDADE? & FLOCOS & & \\
\hline Chandelle & & & Kibon & & \\
\hline Danette & & & Nestlé & & \\
\hline Batavo & & & Creme Mel & & \\
\hline Vigor & & & ITA & & \\
\hline & & & New Cream & & \\
\hline
\end{tabular}

1- Marque um "X” nas marcas que você já consumiu.

2- Marque um “O” nas marcas que você costuma comprar.

3- Geralmente você que faz compras para sua residência?

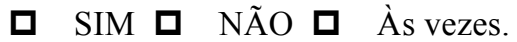

4- Numa escala de 0 a 5, sendo 0 sem importância alguma e 5 muito importante, qual a importância do arroz na sua vida? 
5- Numa escala de 0 a 5, sendo 0 sem importância alguma e 5 muito importante, qual a importância do feijão na sua vida?

6- Numa escala de 0 a 5, sendo 0 sem importância alguma e 5 muito importante, qual a importância do iogurte na sua vida?

7- Numa escala de 0 a 5, sendo 0 sem importância alguma e 5 muito importante, qual a importância do sorvete na sua vida?

8 - Assinale a renda familiar mensal de sua casa:

( ) $\mathrm{R} \$ 510,00$ ( ) Entre $\mathrm{R} \$ 510,00$ e 1.020,00 ( ) Entre R \$ 1.020,00 e R \$ 1.530,00（） Entre R\$

$1.530,00$ e $\mathrm{R} \$ 2.040,00$

（） Entre R \$ 2.040,00 e R \$ 2.550,00（） Entre R\$2.550,00 e R\$ 5.100,00（） Entre R\$ 5.100,00 e R\$

7.650,00 ( ) Entre R\$ 7,650,00 e R \$ 10.200,00 ～～）Acima de R \$ 10.200,00. 